\title{
EFEITOS DOS PISOS SALARIAIS ESTADUAIS SOBRE O MERCADO DE TRABALHO: UMA NOVA ABORDAGEM EMPÍRICA
}

\author{
Carlos Henrique Corseuil * \\ Miguel Foguel ${ }^{+}$ \\ Marcos Hecksher $\ddagger$
}

\begin{abstract}
Resumo
Este trabalho avalia os efeitos dos pisos salariais introduzidos no Paraná e em São Paulo sobre alguns indicadores do mercado de trabalho. Em ambas as Unidades da Federação (UFs), são analisados três grupos ocupacionais distintos com base nos dados da Pesquisa Nacional por Amostra de Domicílios (PNAD/IBGE). Conclui-se que, em um dos grupos de cada UF, a política aumentou a remuneração de trabalhadores que receberiam menos que os respectivos pisos caso estes não tivessem sido criados, sem se contrair o emprego ou se aumentar a informalidade. Nos demais agregados ocupacionais de cada UF, não foi encontrado qualquer efeito significativo da legislação. A maior contribuição deste trabalho é a utilização de uma nova metodologia mais apropriada para identificar efeitos de tratamento em unidades agregadas, apresentada por Abadie et al. (2010).
\end{abstract}

Palavras-chave: pisos salariais; salário mínimo; mercado de trabalho; efeito de tratamento.

\begin{abstract}
This paper evaluates the introduction of Brazilian regional and occupational wage floors on labor market performance. We focus on two out of five states that implemented such intervention: Paraná and São Paulo. In each state, we have analyzed the effects of the wage floors for three distinct occupational categories. Our results point that one occupational group in each state seems to be affected by the introduction of a wage floor. In both cases, the wage floor tends to reduce the share of employees with wages below the established floor without producing side effect on employment or on informality. It was not found any significant effect of the new legislation in the other occupational groups in each state. We innovate on methodological grounds by using the synthetic control method put forward by Abadie et al. (2010).
\end{abstract}

Keywords: wage floors; minimum wages; labor market; treatment effect. JEL classification: J21; J31; J38

DOI: http ://dx.doi .org/10.1590/1413-8050/ea 125210

\footnotetext{
* IPEA - Brasil. E-mail: carlos.corseuil@ipea.gov.br

† IPEA - Brasil. E-mail: miguel.foguel@ipea.gov.br

* IPEA- Brasil e mestrando em População,Território e Estatísticas Públicas da Ence/IBGE. E-mail: marcos.hecksher@ipea.gov.br
} 


\section{Introdução}

Pisos salariais legislados em valores acima do salário mínimo (SM) nacional estão em vigor atualmente em cinco estados brasileiros: Rio de Janeiro (RJ), Rio Grande do Sul (RS), Paraná (PR), São Paulo (SP) e Santa Catarina (SC). Em dois destes estados (RJ e RS), os pisos vigoram há mais de dez anos. No entanto, ainda há poucas avaliações sobre os efeitos dessas medidas em indicadores do mercado de trabalho. Um dos grandes obstáculos para que essa tarefa seja executada é encontrar uma estratégia de identificação que seja ao mesmo tempo convincente e aplicável a um conjunto amplo de indicadores. Uma das principais contribuições deste estudo vem justamente nessas dimensões, ao utilizar uma estratégia ainda inédita nesse tipo de análise.

A estratégia empírica consagrada na literatura internacional para identificar o efeito de pisos salariais estaduais sobre indicadores do mercado de trabalho é o método de diferenças em diferenças. ${ }^{1}$ Para que essa estratégia seja bem-sucedida, supõe-se que a evolução dos indicadores do mercado de trabalho nos estados que criaram ou aumentaram seus pisos salariais seja bem aproximada pela evolução desses indicadores em um conjunto de estados no período pós-intervenção. ${ }^{2}$ Em outras palavras, usa-se a evolução nesse conjunto de estados após a intervenção como uma aproximação do que seria visto nas unidades que sofreram a intervenção caso esta não tivesse sido realizada. Naturalmente, esta suposição não é diretamente testável, mas em algumas aplicações utiliza-se um indicativo indireto da sua validade baseado em testar se o indicador de interesse tem a mesma evolução pré-intervenção. ${ }^{3}$ Em aplicações desse método, também é comum o uso apenas de um estado vizinho para desempenhar o papel de contrafatual.

Este texto emprega, pela primeira vez nesse tipo de análise, a estratégia de identificação proposta por Abadie \& Gardeazabal (2003) e posteriormente formalizada por Abadie et al. (2010). Nessa estratégia, a construção de um contrafatual da evolução do indicador de interesse para o grupo tratado procura combinar informações de todos os demais grupos não tratados. Essa combinação é obtida por intermédio de uma média ponderada em que os pesos visam minimizar a distância entre os dois grupos no período pré-intervenção. Isso torna essa estratégia mais flexível que a de diferenças em diferenças, uma vez que, por construção, ela procura "sintetizar" um grupo de controle similar ao grupo tratado antes da intervenção. ${ }^{4}$ Ademais, como mostra a seção 4 , o modelo por trás da estratégia proposta por Abadie et al. (2010) é mais geral que o de diferenças em diferenças.

\footnotetext{
${ }^{1}$ Card (1992) e, principalmente, Card \& Krueger (1994) podem ser apontados como os principais responsáveis pela consagração dessa estratégia no contexto de avaliações de pisos salariais por dois motivos. Em primeiro lugar, foram pioneiros no uso desta metodologia na literatura de SM. Em segundo, por serem trabalhos que, juntamente com Card \& Krueger (1995), tiveram grande repercussão no debate em torno dos efeitos do SM no mercado de trabalho.

${ }^{2}$ Mais detalhes dessa estratégia podem ser obtidos em Meyer (1995) ou em resenhas metodológicas tais como Angrist \& Krueger (1999) ou BLUNDELL (2009).

${ }^{3}$ No entanto, em muitos casos, esse teste não é feito e a análise é conduzida com a possibilidade de que os grupos de tratamento e de controle sequer tenham tido a mesma trajetória antes da intervenção.

${ }^{4}$ Uma estratégia alternativa, adotada na literatura visando aumentar as chances de o contrafatual reproduzir a evolução do grupo afetado pela política, consiste em empregar o método de diferenças em diferenças restringindo a amostra a áreas perto da divisa entre o estado que sofreu a intervenção e o que não sofreu a intervenção. Este tipo de estratégia é utilizado em Dube et al. (2010) Dube et al. (2011).
} 
Neste estudo, essa estratégia de identificação é empregada para avaliar o efeito dos pisos salariais sobre o mercado de trabalho de dois dos cinco estados que adotaram a política, a saber, PR e SP. Essa escolha se deve ao fato de que os pisos são fixados por grupos ocupacionais definidos pelos próprios estados e somente para esses dois foi possível compatibilizar as listas de ocupações com as da PNAD, a base de dados aqui utilizada. Além disso, houve uma mudança na classificação das ocupações da PNAD a partir de 2002 e para evitar a necessidade de uma segunda compatibilização das ocupações - que poderia reduzir a acurácia dos resultados -, optou-se por utilizar somente as versões da PNAD entre 2002 e 2009. Como a metodologia aqui utilizada requer informações antes da intervenção, somente o PR e SP atendem a condição de terem instituído seus pisos durante esse intervalo.

O método será usado para avaliar o impacto dos pisos salariais nas seguintes variáveis: proporção de empregados com remuneração inferior ao valor do piso de referência; taxa de emprego; taxa de informalidade; e hiato salarial entre empregados com e sem carteira de trabalho assinada. Julga-se ser do interesse do legislador que o piso eleve a remuneração dos trabalhadores que ocupam postos remunerados abaixo do que foi legislado, o que justifica a escolha da primeira variável a ser analisada. No entanto, para que isso efetivamente ocorra, os agentes que interagem no mercado de trabalho devem reagir a um aumento de piso salarial tal como desejado pelo poder público, o que nem sempre ocorre.

A escolha dos demais indicadores foi guiada pelo debate na literatura a respeito da maneira como o mercado de trabalho se ajusta a um aumento de pisos salariais, ou seja, por meio de ajustes no nível de emprego, na sua composição e nos salários praticados nos segmentos formal e informal do mercado de trabalho.

De acordo com o arcabouço teórico clássico sobre $\mathrm{SM}$, as firmas devem reagir ao aumento do piso diminuindo o nível de emprego.Card \& Krueger (1994) Card \& Krueger (1995) contestaram esse resultado mostrando evidências que indicam um efeito nulo ou um pequeno aumento do emprego em decorrência de aumentos de pisos salariais estaduais nos Estados Unidos. ${ }^{5}$ Posteriormente, associaram-se esses efeitos nulos ou positivos no emprego a predições teóricas dos modelos monopsonísticos tradicionais ou de busca por emprego (search models). ${ }^{67}$ Esse debate justifica o interesse na taxa de emprego.

$\mathrm{O}$ citado debate ignora dois pontos relevantes sobre o ajuste do mercado de trabalho à lei dos pisos. O primeiro é a presença do setor informal e o segundo é a possibilidade de cumprimento parcial da lei. Com relação ao primeiro ponto, há indícios de que o ajuste pode ser distinto quando os trabalhadores têm duas alternativas para se empregarem: em um posto formal ou num posto informal. Do ponto de vista teórico, Mincer (1976) trata desse

\footnotetext{
${ }^{5}$ Essas evidências foram contestadas por Neumark \& Wascher (2000), que argumentam que elas são dependentes dos dados utilizados por Card \& Krueger (1994). Roppnen (2011) mostra que, na verdade, o impacto depende do tamanho da firma e, portanto, a diferença de resultados reportados neste debate se devia à diferença na composição das respectivas amostras no que diz respeito ao tamanho das firmas. Debates similares ocorreram em outros países - ver, por exemplo, Garloff (2010) para o caso alemão.

${ }^{6}$ O leitor interessado nessa associação pode consultar Swinnerton (1996) e Masters (1999). Garloff (2010) mostra que, mesmo dentro da classe de modelos de busca, há uma ambiguidade sobre a direção do efeito de pisos salariais sobre o emprego.

${ }^{7}$ Há outras vertentes teóricas capazes de racionalizar o resultado de, Card \& Krueger (1994) Card \& Krueger (1995) o que é comentado em mais detalhes na subseção 5.4.
} 
tema adaptando o arcabouço clássico para incorporar esses dois setores, e mostra que pode haver migração de trabalhadores do setor formal para o informal após a introdução ou a elevação do $\mathrm{SM} .{ }^{8}$ Empiricamente, há diversos trabalhos que apresentam evidências de que o setor informal tende a ser afetado pelo SM. Na realidade, essa influência pode se dar também de forma direta, uma vez que as firmas podem decidir cumprir a legislação sobre os pisos em seus postos informais. ${ }^{9}$ Esses efeitos, diretos ou indiretos, sobre níveis de emprego e salário dos setores formal e informal são um dos motivadores da escolha do indicador de hiato salarial entre empregados com e sem carteira.

Com relação ao segundo ponto, Danziger (2010) reporta que há evidências de cumprimento parcial em pisos salariais para vários países, inclusive para os Estados Unidos. Moura \& Neri (2008) reportam evidências na mesma direção nos primeiros anos de vigência dos pisos estaduais no RJ e no RS. A maneira mais intuitiva de considerar esse problema pode ser exemplificada a seguir. Eventualmente, o piso estadual pode ter efeitos sobre os trabalhadores quando estes estão, de fato, sujeitos à lei. No entanto, se uma grande parcela dos empregadores não cumpre a lei, é de se esperar que tal efeito seja pulverizado em uma análise que agregue tanto os trabalhadores de firmas cumpridoras quanto os de firmas descumpridoras, que mantêm empregados com remuneração menor que o piso. Além disso, o não cumprimento pode alterar de forma menos intuitiva a maneira com que o mercado de trabalho se ajusta (Yaniv 2004, Danziger 2009).

Não há muitas alternativas para contornar o problema de cumprimento parcial dos pisos salariais nos estados brasileiros. O que se faz aqui é apenas inferir em que medida o grau de cumprimento interfere na análise. Como os pisos salariais foram definidos por grupos de ocupação em cada Unidade da Federação (UF) que os adotou, foram conduzidas análises agregadas por UF e também análises estratificadas por grupos ocupacionais com diferentes taxas de cumprimento em cada UF. Dessa forma, é possível verificar se eventuais efeitos para grupos com cumprimento relativamente maior são pulverizados no agregado da UF.

Cabe destacar que uma avaliação dos efeitos dos pisos estaduais sobre indicadores do mercado de trabalho também pode ser útil para uma avaliação dos efeitos do SM nacional, em que a tarefa de encontrar uma estratégia de identificação adequada seria ainda mais árdua. Afinal, o piso nacional é homogêneo em todos os estados, todas as ocupações e todos os setores. A experiência dos pisos estaduais permite ao analista fazer uso de heterogeneidades que não podem ser vistas no mínimo nacional. Além disso, essa experiência por estado ainda permite isolar efeitos diretos sobre o mercado de trabalho daqueles intermediados por transferências públicas de renda, indexadas somente ao SM nacional.

Apesar da utilidade das avaliações dos efeitos dos pisos para mensurar os impactos do SM, há pelo menos três cuidados a serem tomados. Em primeiro

\footnotetext{
${ }^{8}$ Além desses dois setores, o modelo de Mincer (1976) permite a existência do estado de desemprego. Assim, dependendo do hiato salarial que aparece entre os setores formal e informal, é possivel que os trabalhadores prefiram permanecer desempregados à espera de uma vaga no setor formal.

${ }^{9}$ Entre os diversos trabalhos mais recentes que se debruçaram sobre a relação entre o SM e o setor informal no Brasil, ver Fajnzylber (2001), Neri et al. (2001), Soares (2004) e Lemos (2004). Resenhas sobre os impactos do SM no mercado de trabalho no Brasil podem ser encontradas em Corseuil \& Servo (2002) e Ulyssea \& Foguel (2006). Para uma resenha dos efeitos do SM na América Latina, ver Cunningham (2007).
} 
lugar, se os efeitos do SM sobre indicadores de mercado de trabalho variam dependendo do valor do mínimo, os impactos estimados com base nos pisos estaduais podem fornecer uma resposta equivocada para os efeitos do mínimo. Em segundo lugar, se os impactos do mínimo mudam de acordo com o seu grau de cumprimento no mercado de trabalho, como os pisos têm diferentes graus de cumprimento locais relativamente ao do SM, os efeitos computados com o uso dos pisos podem ser pouco informativos acerca dos efeitos do mínimo. Finalmente, como a natureza e a magnitude dos impactos captados com base nos pisos salariais de uma UF podem ser específicas daquela UF, a generalização desses impactos para o âmbito nacional pode ser arriscada.

Este trabalho está organizado em mais cinco seções. A seção 2 descreve o contexto institucional da intervenção analisada, com detalhes relevantes da lei federal que introduziu a possibilidade de diferenciação de pisos salariais nas UFs, bem como aspectos específicos da legislação dos pisos em algumas UFs. Em seguida, a seção 3 traz uma descrição dos dados acompanhada por algumas estatísticas descritivas. A seção 4 apresenta a metodologia e a seção 5, os resultados. Por fim, a seção 6 apresenta as conclusões.

\section{A legislação dos pisos estaduais no Brasil e suas avaliações}

A variedade de pisos salariais legais em diferentes estados brasileiros foi criada a partir de uma autorização expressamente incluída na legislação federal em 2000. Embora a Constituição Federal (Brasil 1988) mantenha o SM nacionalmente unificado, ${ }^{10}$ também prevê que se estabeleça um piso salarial "proporcional à extensão e à complexidade do trabalho" (Brasil, 1988, Artigo $7^{\circ}$, inciso V). Com base nisso, desde 2000, a Lei Complementar (LC) n ${ }^{\circ} 103$ permite que os governos dos estados e do Distrito Federal proponham leis com pisos salariais superiores ao mínimo nacional. Os pisos estaduais devem regular ocupações ou atividades específicas e só valem na ausência de leis federais ou negociações coletivas que fixem outros pisos - superiores ou inferiores aos estaduais, mas nunca menores que o mínimo nacional. É proibido exigir que as administrações municipais cumpram os pisos estaduais. Nem os próprios governos estaduais são obrigados a segui-los, o que limita seu impacto fiscal. ${ }^{11}$

Após a lei federal de 2000, cinco estados passaram a fixar pisos acima do SM: RJ e RS, desde 2001; PR, desde 2006; SP, desde 2007; e SC, desde 2010. Os cinco pertencem às regiões Sul e Sudeste do país, onde já se pagavam salários mais altos que a média nacional, mas há uma grande diversidade de casos. Os valores, as datas de reajuste, as quantidades de faixas e as categorias profissionais ou atividades empresariais que compõem cada faixa variam bastante no espaço e no tempo. O RJ, por exemplo, começou com três faixas diferentes e foi aumentando até chegar às nove atuais, com muitas mudanças nas ocupações inseridas em cada uma. O PR iniciou com cinco faixas e reduziu para três.

\footnotetext{
${ }^{10}$ O SM, fixado pelo governo federal, foi criado no Brasil em 1940 com quatorze valores diferenciados entre estados e sub-regiões. Em 1963, chegou a ter 38 faixas regionais (Saboia 1984). Sua unificação nacional foi estabelecida em 1984.

${ }^{11}$ O RS, desde 2003, decidiu pagar também um complemento a seus servidores ativos e inativos com remuneração inferior ao piso mais alto do estado. Mas, como a lei federal não obriga nenhum estado a fazer isso, a regra geral é que os pisos estaduais só precisam ser pagos pelo setor privado, enquanto os governos estaduais que os propõem não incorrem em custos diretos.
} 
Além de dividir com os governadores parte da pressão por aumentos no SM, um dos propósitos aparentes da lei federal de 2000 era desvincular os pisos do setor privado daqueles que pesam sobre salários e benefícios pagos pelo setor público nas três esferas. No debate sobre políticas para o mercado de trabalho anterior à lei, este era um dos argumentos de Jatobá \& Chahad (1997) e de Neri (1999) em defesa da medida, que faria parte de uma agenda politicamente viável em alternativa à desvinculação explícita entre benefício previdenciário e SM. Em geral, a desvinculação costuma ser proposta para permitir que o SM possa aumentar sem pressionar as contas públicas, enquanto o piso previdenciário passa a ser indexado a algum indicador que tenda a subir mais lentamente. Na proposta de regionalização, resultado semelhante era buscado por um caminho quase inverso: o SM passaria a definir apenas remunerações e benefícios pagos pelo setor público e seria reajustado no ritmo que a política fiscal permitisse, ao passo que os pisos estaduais poderiam subir mais e passar a ser o foco de pressão dos trabalhadores ativos do setor privado, que os negociariam com entidades patronais e governos de seus estados.

Passados quinze anos, observa-se que a valorização real do SM foi intensificada ${ }^{12}$ e a regra de reajuste vigente desde 2008, que acarretou altas superiores às do produto médio por trabalhador, está perto de ter sua extensão até 2019 fixada em nova lei. ${ }^{13}$ Enquanto isso, nos estados que instituíram pisos, os salários pagos pelo setor privado sempre aderiram bem menos aos pisos estaduais que ao mínimo nacional, embora a fiscalização de ambos esteja a cargo do Ministério do Trabalho e Emprego (MTE). Dois outros estudos, descritos a seguir, constataram este alto descumprimento de pisos estaduais.

Por meio de regressões quantílicas com microdados longitudinais de 2000 a 2001 da Pesquisa Mensal de Emprego (PME/IBGE), Moura \& Neri (2008) observaram um baixo cumprimento dos pisos logo após sua criação no RJ e no RS. Tomando os trabalhadores de SP como grupo de controle, os autores encontraram efeito estatisticamente nulo da política sobre os níveis de salário e de emprego nos dois estados que a adotaram em 2001.

Com base em microdados de 2006 a 2008 da Pesquisa Nacional por Amostra de Domicílios (PNAD/IBGE), Chahad \& Pereda (2010) investigaram a efetividade das três faixas de pisos vigentes em SP em 2007 e 2008. Utilizando Minas Gerais (MG) como grupo de controle em um modelo logit ordenado, os autores concluíram que a lei podia ser considerada efetiva nas duas primeiras faixas salariais, embora o cumprimento não fosse alto.

\section{Dados}

Para avaliarem-se os graus de cumprimento e descumprimento dos pisos e seus efeitos sobre indicadores do mercado de trabalho, o primeiro passo é saber a quem se aplica cada valor fixado nas leis estaduais. Essa questão, no entanto, só admite uma resposta inequívoca no PR e a partir de 2007, pois, desde então, os pisos paranaenses passaram a ser explicitamente associados

\footnotetext{
${ }^{12}$ A média móvel em 12 meses anteriores do salário mínimo real subiu 4,0\% ao ano entre julho de 1995 e julho de 2000, quando foi publicada a lei federal que autorizou os pisos estaduais. Desde então, a alta média foi de $4,9 \%$ ao ano.

${ }^{13}$ Pela regra adotada desde 2008 e fixada na Lei no $12.382 / 2011$, o SM recebe, a cada ano, um aumento real igual ao último dado anual disponível de crescimento real do produto interno bruto (PIB). Até 2014, como a população ocupada cresceu inclusive nos anos de crise, o PIB cresceu mais que o PIB por trabalhador.
} 
na lei a grandes grupos (GG) da classificação brasileira de ocupações (CBO), seguida de forma exata nesse nível mais alto de agregação pela base utilizada neste estudo, os microdados da PNAD. Nos demais estados e no próprio PR em 2006, as leis definem pisos para listas de ocupações específicas que nem sempre correspondem à nomenclatura utilizada pela PNAD ou por qualquer outra pesquisa. É o caso dos pisos de SP, analisados neste trabalho após uma compatibilização entre definições feita pelos próprios autores, provavelmente com algumas diferenças em relação às utilizadas em outros estudos. Vale dizer que a maneira como as leis são redigidas dá margem a interpretações variadas não apenas entre os avaliadores de tais políticas, mas também entre empregados, empregadores, sindicatos, fiscais, procuradores e juízes do trabalho, ou até mesmo entre membros dos próprios governos estaduais e das assembleias que as formularam.

Além disso, até 2001, a PNAD adotava outra classificação de ocupações. Para evitar a necessidade de uma segunda compatibilização própria, que poderia reduzir a precisão da análise, este trabalho se concentra no período de 2002 a 2009, explorando, portanto, as oito últimas edições da PNAD da década de 2000. Como a metodologia aqui empregada requer dados do período antes da intervenção, o estudo avalia somente os efeitos de pisos instituídos durante este intervalo: os do PR, criados em 2006, e os de SP, criados em 2007.

Os grupos ocupacionais de cada estado utilizados na análise foram agrupados da seguinte forma. No caso de SP, faz-se uso exatamente dos grupos definidos pelo estado, ou seja, as informações estão desagregadas nos grupos 1,2 e 3 , que correspondem, respectivamente, às ocupações associadas às faixas de pisos I, II e III na legislação paulista, conforme detalha a tabela A.2 do Apêndice A. No caso do PR, para evitar estatísticas baseadas em poucas observações amostrais, optou-se por agregar em apenas três grupos, a partir daqui denominados 5, 6 e 8, as ocupações que a lei paranaense distribuiu por seis faixas de pisos de 2007 a 2009 (tabela A.1 do Apêndice A). O denominado grupo 5 do PR corresponde ao GG 5 da CBO, integralmente coberto pela faixa de piso II desde 2007 até 2009. Por sua vez, os GGs 7 e 8 da CBO, compostos por trabalhadores da indústria cobertos pela mesma faixa de piso $\mathrm{V}$ do $\mathrm{PR}$ entre 2007 e 2009, foram agregados no que aqui se chama de grupo 8. Finalmente, o grupo 6 também poderia ser chamado de "outros", pois agrega os GGs 3, 4, 6 e 9 da CBO, que, isoladamente, na amostra da PNAD, têm poucas observações a cada ano, tanto no PR como em outras UFs. ${ }^{14}$

É possível tomar diferentes definições para o cumprimento e o descumprimento de um piso quando se pretende quantificá-los. Para identificar os rendimentos iguais aos pisos, optou-se neste estudo por incluir em tal conjunto, ao redor dos valores exatos de cada piso legal, intervalos que contivessem duas dezenas redondas como limites inferior e superior, pois é nesses valores múltiplos de $\mathrm{R} \$ 10$ que se concentra a maioria dos salários reportados na PNAD. Tendo em vista que os cumpridores do piso podem arredondar seus valores nos contratos de trabalho ou na informação prestada ao entrevistador, aceitouse que uma observação na pesquisa com renda de $\mathrm{R} \$ 560$, por exemplo, fosse considerada "igual ao piso" da categoria se a lei o tivesse fixado em R $\$ 550$, em R \$569,99 ou em qualquer quantia intermediária. Nas estatísticas a seguir,

\footnotetext{
${ }^{14}$ Até 2003, a PNAD não cobria as áreas rurais de Acre (AC), Amapá (AP), Amazonas (AM), Pará (PA), Rondônia (RO) e Roraima (RR). Neste trabalho, só foram mantidas na base as observações desses estados coletadas em área urbanizada, mesmo de 2004 a 2009, para que as estatísticas de cada UF se referissem sempre aos mesmos territórios.
} 
este critério evita que as porcentagens de salários iguais aos pisos fiquem altas somente nos pisos com valores exatos múltiplos de $\mathrm{R} \$ 10$, mas, naturalmente, não impede que as frequências permaneçam mais elevadas quando os pisos são iguais ou próximos a múltiplos de $\mathrm{R} \$ 100$, por exemplo.

Mesmo após essa definição, ainda é possível adotar variadas taxas como indicadores de cumprimento. Uma delas é a razão entre o número de pessoas com salário igual ao piso e o total de trabalhadores nas ocupações elegíveis. Outra opção é incluir no numerador todos os trabalhadores com salário igual ou maior que o piso. É possível também mudar o grupo considerado elegível de várias formas, excluindo da conta os trabalhadores com renda menor que o SM ou aqueles com renda muito superior aos pisos, acima de alguma linha arbitrária qualquer. A conta pode ser feita somente para os empregados do setor privado com carteira assinada ou pode incluir outros grupos de ocupados, como empregados sem carteira e trabalhadores por conta própria. A própria renda do trabalho pode estar convertida ou não, pelo número de horas trabalhadas, a um valor proporcional à jornada de 44 horas semanais a que se referem os pisos legais.

A tabela 1 apresenta os valores dos pisos salariais de cada grupo ocupacional definido no PR e em SP. Esses são os valores utilizados (com os devidos ajustes discutidos anteriormente) para marcar quem tem remuneração igual ao piso salarial de seu respectivo estado e grupo ocupacional. Isso vale também para o caso PR, onde se implementou uma agregação dos grupos ocupacionais para fins de análise.

Tabela 1: Valores dos pisos salariais legais do PR e SP por ano e mês

\begin{tabular}{lcccc}
\hline Paraná & & & & \\
\hline Ano & 2006 & 2007 & 2008 & 2009 \\
Mês & Junho & Maio & Maio & Maio \\
Piso I & 427,00 & 462,00 & 527,00 & 605,52 \\
Piso II & 429,12 & 464,20 & 531,00 & 610,12 \\
Piso III & 431,28 & 466,40 & 535,00 & 614,72 \\
Piso IV & 433,44 & 468,60 & 540,00 & 620,46 \\
Piso V & 435,61 & 473,00 & 544,00 & 625,06 \\
Piso VI & 437,80 & 475,20 & 548,00 & 629,65 \\
\hline São Paulo & & & \\
\hline Mês & Agosto & Maio & Maio \\
Piso I & 410,00 & 450,00 & 505,00 & \\
Piso II & 450,00 & 475,00 & 530,00 & \\
Piso III & 490,00 & 505,00 & 545,00 \\
\hline \multicolumn{5}{l}{ Fontes: MTE e assembleias legislativas dos estados. } \\
Elaboração dos autores.
\end{tabular}

Optou-se aqui por apresentar dados para empregados do setor privado com carteira ou sem carteira de trabalho assinada - em ocupações elegíveis para os pisos de cada estado de análise, classificados em faixas de renda associadas ao SM e ao respectivo piso de acordo com suas remunerações mensais do trabalho principal, sem levar em conta o tamanho das jornadas de trabalho. 
As tabelas 2 e 3 mostram respectivamente para o PR e SP a distribuição dos trabalhadores da amostra selecionada segundo diferentes faixas de rendimento definidas pelos pisos de cada estado e o salário mínimo nacional. No PR, na média de 2007 a 2009, quando os pisos se referem à totalidade dos grupos analisados, havia aproximadamente 2,6 milhões de empregados - dos quais, 1,8 milhão com carteira - em ocupações com pisos definidos na lei estadual. Esses trabalhadores com piso representavam 91\% dos empregados em ocupações bem definidas nos dados da PNAD relativos ao estado. Em SP, de 2007 a 2009, com os pisos referindo-se sempre a ocupações específicas, havia aproximadamente 6,5 milhões de empregados (4,6 milhões com carteira) legalmente cobertos pelos pisos, o equivalente a $52 \%$ dos que tinham ocupações bem definidas na base para o estado.

Para anos anteriores à criação dos pisos, foram obtidas taxas simuladas com base nos valores iniciais de cada piso, deflacionados pelo INPC do IBGE e ajustados para as datas de recebimento dos salários informados na PNAD, conforme série disponível no site Ipeadata. ${ }^{15}$ Nas tabelas 2 e 3, essas taxas simuladas ajudam a extrair uma primeira impressão sobre possíveis efeitos da criação dos pisos sobre as distribuições salariais. Adiante, elas serão úteis para encontrar unidades com distribuições salariais semelhantes ao longo dos anos em que os pisos ainda não existiam.

As tabelas 2 e 3 confirmam que, de modo geral, o contingente com renda igual ao piso é pequeno e o com renda menor que o piso é grande, o que indica alto grau de descumprimento da legislação estadual, especialmente no PR, onde os valores fixados são mais altos. As porcentagens na faixa considerada igual ao piso oscilam bastante e às vezes se tornam bem mais altos quando os valores legais caem em algum intervalo que inclua uma centena redonda. Parte dessa oscilação ocorre porque essa estatística se baseia em poucas observações da amostra.

As porcentagens com renda menor que o piso apresentam trajetórias mais bem definidas, em geral, caindo logo após a introdução da política e subindo quando os pisos são fortemente aumentados, como no PR em 2008 e 2009. A Figura 1 mostra em quanto as faixas de piso do PR e de SP superam o SM nacional a cada ano, o que ilustra a "dose do remédio" ministrado a cada grupo de tratamento, ano a ano. Vale lembrar que as diferenças mostradas na figura, como o aumento no PR em 2008 e 2009, referem-se a níveis também crescentes do próprio SM, que, no mesmo biênio, subiu $4,6 \%$ ao ano (a.a.) em termos reais, gerando efeitos em todo o país. Porém, ao avaliar o impacto específico dos pisos introduzidos no PR ou em SP, o que se analisa é o efeito dessas trajetórias exibidas na Figura 1.

${ }^{15}$ Disponível em: http://www.ipeadata.gov.br/. Vale dizer que, embora tenhamos empregado o INPC geral para o país, as diferenças de variação do índice no período analisado são pequenas entre as regiões metropolitanas (RM) que compõem o INPC. Por exemplo, o INPC brasileiro subiu em média 7\% a.a. de 2002 a 2007, enquanto seus componentes da RM de Curitiba e da RM de São Paulo subiram ambos 6,2\% a.a. A análise também foi realizada sem deflacionamento e os resultados foram qualitativamente muito semelhantes. 
Tabela 2: Distribuição dos empregados por faixa de estadual de rendimento no PR (2005-2009) - Em \%

\begin{tabular}{|c|c|c|c|c|c|c|}
\hline & & $2005^{(1)}$ & $2006^{(2)}$ & 2007 & 2008 & 2009 \\
\hline \multirow{6}{*}{ Piso II } & Menor que o piso & 64,6 & 55,3 & 51,8 & 56,7 & 64,9 \\
\hline & Menor que o SM & 25,2 & 26,9 & 24,8 & 25,2 & 27,9 \\
\hline & Igual ao SM & 19,7 & 17,6 & 11,6 & 13,2 & 12,3 \\
\hline & Entre o SM e o piso & 19,7 & 10,8 & 15,4 & 18,3 & 24,7 \\
\hline & Igual ao piso & 1,4 & 2,9 & 2,4 & 3,3 & 2,5 \\
\hline & Maior que o piso & 34,0 & 41,8 & 45,8 & 40,0 & 32,7 \\
\hline \multirow{6}{*}{ Pisos I, III, IV e VI } & Menor que o piso & 30,5 & 20,9 & 23,8 & 26,4 & 25,6 \\
\hline & Menor que o SM & 5,8 & 5,6 & 7,8 & 6,7 & 6,5 \\
\hline & Igual ao SM & 9,4 & 8,8 & 5,9 & 6,6 & 7,1 \\
\hline & Entre o SM e o piso & 15,3 & 6,5 & 10,1 & 13,1 & 12,0 \\
\hline & Igual ao piso & 1,3 & 1,4 & 1,2 & 1,6 & 7,4 \\
\hline & Maior que o piso & 68,2 & 77,7 & 75,1 & 72,0 & 67,0 \\
\hline \multirow{6}{*}{ Piso V } & Menc & 36,4 & 28,1 & 28,7 & 31,6 & 37,0 \\
\hline & Menor que o SM & 6,7 & 8,4 & 7,3 & 5,6 & 6,0 \\
\hline & Igual ao SM & 10,9 & 10,2 & 7,6 & 7,9 & 6,8 \\
\hline & Entre o SM e o piso & 18,8 & 9,4 & 13,7 & 18,2 & 24,2 \\
\hline & Igual ao piso & 1,2 & 2,5 & 3,1 & 3,6 & 1,5 \\
\hline & Maior que o piso & 62,4 & 69,5 & 68,2 & 64,8 & 61,5 \\
\hline \multirow{6}{*}{ Todos com piso no PR } & Menor que o piso & 46,3 & 37,7 & 37,2 & 40,3 & 45,1 \\
\hline & Menor que o SM & 14,0 & 15,5 & 14,9 & 13,8 & 15,0 \\
\hline & Igual ao SM & 14,1 & 13,0 & 8,9 & 9,7 & 9,1 \\
\hline & Entre o SM e o piso & 18,2 & 9,2 & 13,5 & 16,8 & 21,0 \\
\hline & Igual ao piso & 1,3 & 2,4 & 2,3 & 2,9 & 3,5 \\
\hline & Maior que o piso & 52,4 & 59,9 & 60,4 & 56,7 & 51,4 \\
\hline
\end{tabular}

Fonte: PNAD/IBGE. Elaboração dos autores.

Notas: (1) Porcentagens de 2005 com base no valor do menor piso inicial, criado em 2006, deflacionado pelo Índice nacional de Preços ao Consumidor (INPC/IBGE). ${ }^{(2)}$ Porcentagens para todos os grupos em 2006 com base no menor piso inicial. Em 2006, o PR tinha seis valores de pisos entre $\mathrm{R} \$ 427,00$ e $\mathrm{R} \$ 437,80$, só para ocupações específicas, que representavam $36 \%$ dos ocupados no grupo 5 ; $38 \%$ no grupo 6 ; e $64 \%$ no grupo 8 . Todas as ocupações dos três grupos passaram a ter piso a partir de 2007. 
Tabela 3: Distribuição dos empregados por faixa de estadual de rendimento em SP (2006-2009) - Em \%

\begin{tabular}{lcrrrr}
\hline & & $2006^{(1)}$ & 2007 & 2008 & 2009 \\
Piso I & Menor que o piso & 41,9 & 37,5 & 34,0 & 32,7 \\
& Menor que o SM & 19,6 & 17,0 & 19,0 & 18,3 \\
& Igual ao SM & 20,5 & 12,6 & 14,0 & 12,5 \\
& Entre o SM e o piso & 1,8 & 7,8 & 1,8 & 1,9 \\
& Igual ao piso & 8,2 & 4,1 & 6,0 & 7,6 \\
& Maior que o piso 49,9 & 58,5 & 59,3 & 59,7 & \\
\hline \multirow{4}{*}{ Piso II } & Menor que o piso & 21,3 & 16,3 & 13,5 & 16,4 \\
& Menor que o SM & 6,0 & 5,1 & 4,9 & 5,1 \\
& Igual ao SM & 7,2 & 4,8 & 5,2 & 5,0 \\
Piso III & Entre o SM e o piso & 8,0 & 6,4 & 3,4 & 6,3 \\
& Igual ao piso & 0,8 & 2,8 & 0,9 & 0,4 \\
& Maior que o piso & 77,9 & 80,9 & 85,6 & 83,1 \\
\hline Menor que o piso & 9,2 & 8,4 & 3,8 & 4,5 \\
& Menor que o SM & 2,5 & 2,3 & 1,9 & 1,7 \\
& Igual ao SM & 2,3 & 2,0 & 0,7 & 1,2 \\
& Entre o SM e o piso & 4,4 & 4,1 & 1,2 & 1,7 \\
& Igual ao piso & 0,2 & 4,3 & 3,0 & 1,3 \\
& Maior que o piso & 90,6 & 87,3 & 93,3 & 94,2 \\
\hline & Menor que o piso & 30,1 & 25,3 & 22,3 & 23,1 \\
& Menor que o SM & 12,2 & 10,3 & 11,0 & 11,1 \\
& Igual ao SM & 13,2 & 8,1 & 8,8 & 8,2 \\
& Entre o SM e o piso & 4,8 & 6,9 & 2,5 & 3,8 \\
& Igual ao piso & 4,3 & 3,5 & 3,4 & 4,0 \\
& Maior que o piso & 65,6 & 71,2 & 74,3 & 72,9 \\
\hline & & & & &
\end{tabular}

Fonte: PNAD/IBGE. Elaboração dos autores.

Nota: (1) Porcentagens de 2006 com base no valor de cada piso criado em 2007, deflacionado pelo INPC.

\section{Metodologia}

\subsection{Especificação do modelo}

Para computar os efeitos dos pisos estaduais, este trabalho usa o método do grupo de controle sintético inicialmente proposto por Abadie \& Gardeazabal (2003) e posteriormente formalizado por Abadie et al. (2010). O método baseia-se na construção de um grupo de comparação que seja o mais assemelhado - em um sentido explicitado adiante - ao grupo de tratamento antes da intervenção. A ideia básica é que, se o grupo de controle sintético tem comportamento similar ao da unidade tratada até o início da intervenção, então é de se esperar que as diferenças nas variáveis de resultado que porventura apareçam entre os dois grupos após o programa representem o efeito de interesse.

Uma das principais vantagens do método é que ele procura combinar as unidades que comporão o grupo de controle sintético de forma flexível. Utilizando informações sobre a própria variável de resultado e um conjunto de preditores dessa variável, o método busca um vetor de pesos para as potenciais unidades formadoras do grupo de controle, de tal forma que o grupo 


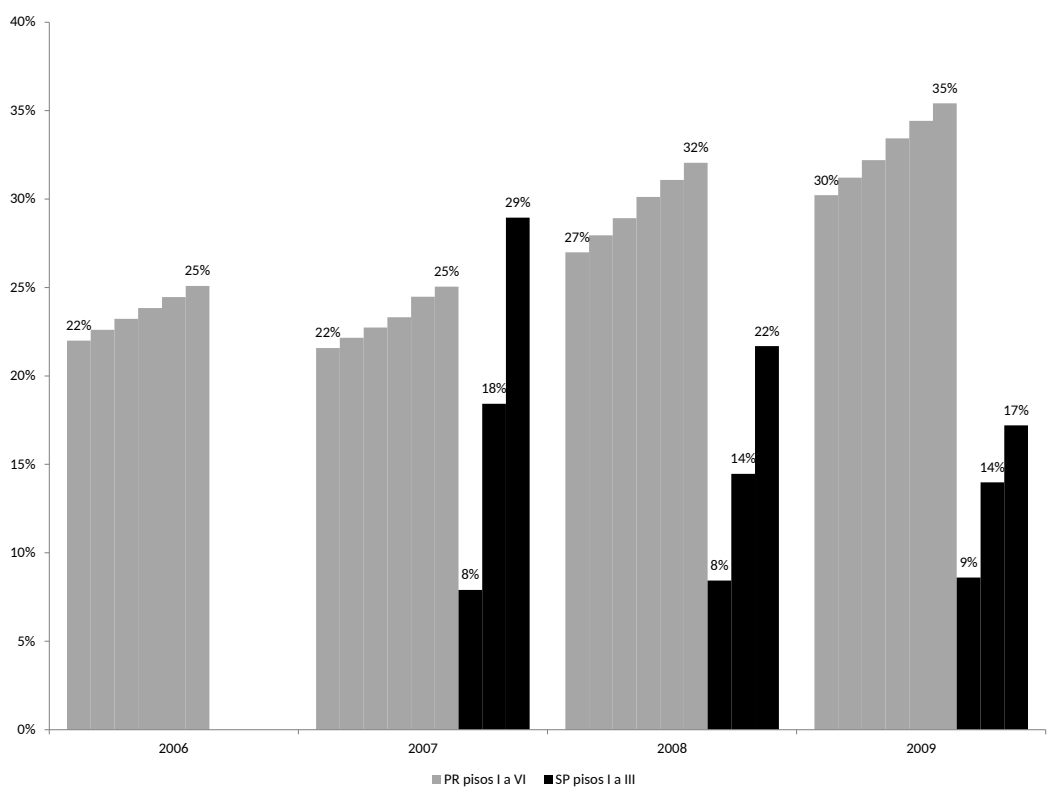

Fonte: Assembleias legislativas dos estados. Elaboração dos autores.

Nota: As alturas das barras para cada estado correspondem às diferenças dos pisos dos respectivos grupos referenciados em algarismos romanos de forma crescente.

Figura 1: Pisos salariais de PR e SP: diferenças sobre o SM nas datas das PNADs (2006-2009)

sintético final seja bem próximo às características da unidade tratada previamente à intervenção. Outros métodos que utilizam um grupo de controle construído a partir de potenciais unidades de comparação, como o diferenças em diferenças, tendem a ser não somente menos flexíveis, mas também menos transparentes, uma vez que são frequentemente baseados em percepções subjetivas dos analistas sobre as semelhanças entre os grupos de tratamento e comparação. Além disso, a escolha de uma unidade como grupo de controle nem sempre é feita sem que o analista já tenha, antes de realizar a estimação, informações sobre a evolução de seus indicadores no período da intervenção. Nesse sentido, um grupo de controle sintético é também composto de forma mais "cega", a partir de critérios objetivos. ${ }^{16}$

A fim de formalizar o funcionamento do método, suponha que existem informações sobre $J+1$ unidades (no caso, UFs) e que apenas uma delas seja a unidade tratada (SP ou PR). As demais $J$ unidades, portanto, formarão um conjunto de unidades que poderão compor o grupo de controle sintético (esse conjunto é denominado de conjunto de unidades doadoras). Assuma que as $J$ unidades doadoras não tenham sido nem direta nem indiretamente afetadas pela intervenção. Na prática, é difícil verificar se as potenciais unidades de controle não foram de fato afetadas indiretamente pela intervenção. Quanto a isso, assim como em outros métodos, cabe ao analista ser criterioso na seleção do conjunto de unidades de comparação.

\footnotetext{
${ }^{16} \mathrm{O}$ método do grupo de controle sintético é particularmente apropriado para análises de efeitos de intervenções em unidades agregadas, como é o caso da política de pisos salariais por grupos ocupacionais das UFs em foco neste artigo. Uma das vantagens do uso de dados agregados é que ele tende a minorar erros de medida tipicamente presentes em dados no nível do indivíduo.
} 
Suponha que nos dados existam $t=1, \ldots, T$ períodos de observação, sendo $t=1, \ldots, T_{0}$ o intervalo pré-tratamento, ${ }^{17}$ com $T_{0}<T$. No caso do PR, por exemplo, $t=2002, \ldots, 2009 \mathrm{com} T_{0}=2005$.

Seja $Y_{i t}^{I}$ a variável de resultado da unidade $i$ no período $t$ se esta unidade for tratada e $Y_{i t}^{N}$ a mesma variável de resultado para a unidade $i$ no período $t$ caso esta unidade não fosse tratada. Como $Y_{i t}^{N}$ representa o contrafatual da variável de resultado, é possível definir o efeito do programa para a unidade $i$ no tempo $t$ como: $a_{i t}=Y_{i t}^{I}-Y_{i t}^{N}$. Assim, utilizando a notação de resultados potenciais, o analista observa para a unidade $i$ no período $t: Y_{i t}=Y_{i t}^{N}+a_{i t} D_{i t}$, onde $D_{i t}$ é uma variável que assume valor unitário se a unidade $i$ for exposta à intervenção em $t$ e valor nulo caso contrário. Sem perda de generalidade, considerando $i=1$ como a unidade tratada (SP ou PR neste trabalho), o objetivo é estimar a sequência $\left\{a_{1 T_{n}+1}, \ldots, a_{1 T}\right\}$.

Dado que $Y_{1 t}^{I}$ é observado diretamente dos dados, resta encontrar um modo de estimar o contrafatual $Y_{1 t}^{N}$. Abadie et al. (2010) propõem o seguinte processo que gera os valores desta variável:

$$
Y_{1 t}^{N}=\delta_{t}+\theta_{t} Z_{i}+\pi_{t} \mu_{i}+\varepsilon_{i t},
$$

em que $\delta_{t}$, denota um fator comum a todas as unidades no período $t, Z_{i}$ representa um vetor $(r \times 1)$ de características preditoras da variável de resultado, $\theta_{t}$ é um vetor $(1 \times r)$ de parâmetros, $\pi_{t}$ é um vetor $(1 \times F)$ de fatores comuns que entra no processo gerador multiplicando o vetor $(F \times 1)$ de factor loadings $\mu_{i}$ e $\varepsilon_{i t}$ é um choque aleatório com média zero. ${ }^{18}$

O próximo passo é encontrar o vetor de pesos para combinar as $J$ unidades doadoras em um grupo de controle sintético. Seja $W=\left(w_{2}, \ldots, w_{J+1}\right)$ um vetor de pesos tal que $0 \leq w_{j} \leq 1, j=2, \ldots, J$ e $\sum_{j=2}^{J+1} w_{j}=1$. Cada vetor distinto $W$ corresponde a um grupo de controle sintético potencial, de forma que, com base nos dados observados para $Y$ e $Z$ das unidades doadoras e no processo que gera a variável de resultado proposto em 1, é possível escrever:

$$
\sum_{j=2}^{J+1} w_{j} Y_{j t}=\delta_{t}+\theta_{t} \sum_{j=2}^{J+1} w_{j} Z_{j}+\pi_{t} \sum_{j=2}^{J+1} w_{j} \mu_{j}+\sum_{j=2}^{J+1} w_{j} \varepsilon_{j t} .
$$

Suponha que exista um vetor de pesos $W^{*}=\left(w_{2}^{*}, \ldots, w_{j+1}^{*}\right)$ tal que:

$$
\sum_{j=2}^{J+1} w_{j}^{*} Y_{j 1}=Y_{11}, \ldots, \sum_{j=2}^{J+1} w_{j}^{*} Y_{j T_{0}}=Y_{1 T_{0}} e \sum_{j=2}^{J+1} w_{j}^{*} Z_{j=1} .
$$

\footnotetext{
${ }^{17}$ Assume-se que a intervenção não tenha impactos nas variáveis de resultado antes de $T_{0+1}$, via efeitos antecipatórios por exemplo. Note-se que, quando existam efeitos desse tipo, o período $T_{0}$ pode ser incluído no intervalo em que o efeito do programa já está potencialmente operando.

${ }^{18}$ Note que, ao permitir que o efeito de características não observadas da unidade $i$ varie no tempo, esse modelo torna-se mais geral que o tradicionalmente empregado na abordagem de diferenças-em-diferenças. Neste último, $\pi_{t}$ assumiria um valor constante para todos os períodos de tempo, o que permitiria eliminar o fator não-observável $\mu_{i}$ ao se computar a diferença da equação 1 entre períodos de tempo.
} 
Abadie et al. (2010) mostram que, sob certas condições de regularidade padrão, ${ }^{19}$ a diferença

$$
Y_{1 t}^{N}-\sum_{j=2}^{J+1} w_{j}^{*} Y_{j t}
$$

será próxima de zero, ou seja, o vetor $W^{*}$ permite criar uma média ponderada da variável de resultado observada nas unidades doadoras cujo valor é muito próximo do contrafatual da unidade tratada para o período $t$. Mas isso é o que geralmente se busca nos métodos não experimentais de avaliação de impactos de programas. Assim, utilizando essa média ponderada, tem-se uma estimativa não-viesada do impacto de interesse no período $t: \widehat{a_{i t}}=Y_{1 t}-\sum_{j=2}^{J+1} w_{j}^{*} Y_{j t}$. O último passo do método é encontrar o vetor $W^{*} .^{20}$

Seja $X_{1}$ uma matriz $(k \times 1)$ que contém os valores das características $Z_{1}$ e da variável de resultado (e/ou combinações lineares dela) para a unidade tratada no intervalo pré-intervenção. Por exemplo,

$$
X_{1}=\left(Z_{1}, Y_{11}, \ldots, Y_{1 T_{0}}, T_{0}^{-1} \sum_{t=1}^{T_{0}} Y_{1 t}\right)
$$

Denotando por $X_{0}$ a matriz $k \times j$ com as mesmas variáveis de $X_{1}$ para as $j$ unidades doadoras, o método procura minimizar a distância $\left\|X_{1}-X_{0} W\right\|$. Para essa minimização, Abadie et al. (2010) propõem utilizar uma matriz $V,(k \times k)$ simétrica e positiva semidefinida, que mede a distância de interesse por meio da fórmula:

$$
\left\|X_{1}-X_{0} W\right\|_{V}=\sqrt{\left(X_{1}-X_{0} W\right) V\left(X_{1}-X_{0} W\right)} .
$$

A matriz $V$ será, portanto, uma matriz que estará (implicitamente) dando peso às variáveis que compõem a matriz de diferença $X_{1}-X_{0} W$.

Notando que a escolha de $V$ influencia o erro quadrático médio (EQM) do estimador proposto, Abadie et al. (2010) seguem o procedimento já adotado em Abadie \& Gardeazabal (2003), a saber: $V$ foi escolhida entre as matrizes diagonais e positivas definidas de forma a minimizar o EQM predito da variável de resultado durante o período pré-intervenção. Este artigo segue o mesmo procedimento.

\subsection{Operacionalização}

Para estimar os efeitos dos pisos regionais, delimitou-se a amostra para incluir somente os trabalhadores do setor privado empregados com ou sem carteira.

\footnotetext{
${ }^{19}$ As principais condições de regularidade são que a matriz $\sum_{t=1}^{T_{0}} \pi_{t}^{\prime} \pi_{t}$ seja não-singular e que o número de períodos de tempo pré-intervenção seja elevado relativamente à escala dos choques aleatórios $\varepsilon_{i t}$.

${ }^{20} \mathrm{Na}$ prática, pode ocorrer de não existir um vetor de pesos que faça a diferença $Y_{i t}^{N}-\sum_{j=2}^{J+1} w_{j}^{*} Y_{j t}$ ser próxima de zero. Isso ocorrerá quando $\left\{\left(Y_{11}, \ldots, Y_{1 T_{0}}, Z_{1}^{\prime}\right)\right\}$ não pertencer ao conjunto convexo formado por $\left\{\left(Y_{21}, \ldots, Y_{2 T_{0}}, Z_{2}^{\prime}\right), \ldots,\left(Y_{j+11}, \ldots, Y_{j+1 T_{0}}, Z_{j+1}^{\prime}\right)\right\}$.
} 
Adicionalmente, restringiu-se a amostra para o conjunto de trabalhadores cujas ocupações estejam em um dos grupos ocupacionais para os quais há um piso salarial definido nas respectivas legislações de SP e PR (ver seção 3). Essa delimitação se deve ao fato de que, pelo menos em princípio, esses são os trabalhadores mais diretamente afetados pela intervenção. ${ }^{21}$

O conjunto de unidades doadoras foi definindo com base na exclusão das UFs que possuem uma política de piso salarial ocupacional. Assim, como até 2009 havia quatro UFs que tinham essa política estabelecida (RJ, RS, PR e SP), o conjunto de UFs doadoras para SP ou PR foi composto pelas 23 demais UFs do país. ${ }^{22}$ Quando o nível de análise passa a ser o grupo ocupacional, o conjunto de unidades doadoras foi formado por até três grupos ocupacionais de cada uma destas 23 UFs. Foram excluídos apenas, do total de 69 grupos disponíveis, aqueles que tivessem, em algum ano, menos de trinta observações de interesse na base para compor o numerador dos indicadores analisados ou taxas de $100 \%$ nesses indicadores. Apresentamos na tabela 3 do Apêndice A uma síntese de estatísticas referentes a frequência amostral de cada UF. ${ }^{23}$

Foram estimados efeitos dos pisos do PR e de SP nas seguintes variáveis de resultado $(\mathrm{Y})$ :

- porcentagem situada abaixo dos pisos analisados: proporção dos empregados cujo salário no trabalho principal se encontrava estritamente abaixo do valor do piso do grupo de tratamento analisado; ${ }^{24}$

- taxa de emprego: razão entre o total de empregados com ou sem carteira no grupo e o total de indivíduos na população em idade ativa (PIA) da UF, definida como população com 10 anos de idade ou mais;

- grau de informalidade: proporção dos sem carteira no total de empregados com renda de até $1,5 \mathrm{SM} ;{ }^{25} \mathrm{e}$

- hiato salarial formal-informal: logaritmo natural da razão entre a média salarial dos empregados com carteira e a dos sem carteira.

Vale observar que a porcentagem situada abaixo do piso não representa uma variável de resultado típica. No entanto, a análise do "efeito" dos pisos

\footnotetext{
${ }^{21}$ Como mencionado na seção 3, esse grupo é amplo, representando $91 \%$ e 52\% dos empregados no PR e em SP, respectivamente. O método empregado neste artigo procura encontrar um grupo de controle sintético com base em informações agregadas dos trabalhadores que se encontram nas mesmas ocupações das demais UFs doadoras. Embora nada garanta que os trabalhadores dessas ocupações sejam parecidos entre as UFs em características não observáveis, o método implicitamente controla para diferenças agregadas entre a UF de tratamento e as UFs doadoras. Naturalmente, há sempre um problema de validade externa, ou seja, não é possível garantir que os resultados obtidos para a UF de tratamento possam ser estendidos para (os mesmos grupos ocupacionais) de UFs não tratadas.

${ }^{22}$ Como só introduziu uma política de pisos salariais em 2010, SC pertence ao conjunto de UFs doadoras.

${ }^{23}$ Tabelas com o número de observações anuais em cada grupo de cada UF utilizada nas estimações podem ser requisitadas aos autores.

${ }^{24}$ Ao estudar o efeito sobre esse indicador no grupo 6 do PR, utiliza-se o menor dos pisos deste grupo (faixa I) como referência para todas as observações da base. Quando a unidade tratada em análise é uma UF agregada (PR ou SP), a referência para cada observação é o piso associado ao seu respectivo grupo ocupacional na UF tratada.

${ }^{25} \mathrm{Em}$ princípio, os trabalhadores por conta-própria não têm seus rendimentos vinculados nem aos valores estabelecidos para os pisos estaduais nem ao salário mínimo. Por essa razão, esse indicador utiliza apenas assalariados sem carteira assinada para medir o impacto de interesse sobre a informalidade.
} 
salariais sobre ela é importante, uma vez que o cumprimento ou descumprimento da lei pode ser interpretado como o principal canal pelo qual a política afetará outras variáveis do mercado de trabalho. Outra observação sobre a escolha das variáveis é que não foi incluída nem a taxa de desemprego nem a taxa de participação. A exclusão se deve ao fato de que a análise empírica foi realizada somente para os trabalhadores que se encontravam nas categorias ocupacionais cobertas pelas respectivas legislações estaduais dos pisos salariais de SP ou PR. Por isso, não seria possível demarcar com os dados disponíveis quem é desocupado para certas ocupações.

No modelo proposto por Abadie et al. (2010), as matrizes $\left(X_{1}, X_{0}\right)$ são formadas pelas variáveis preditoras em $Z$ e a própria variável $Y$ (e/ou combinações lineares de seus valores) no período pré-programa. Os resultados aqui obtidos foram baseados na construção de $\left(X_{1}, X_{0}\right)$ que envolveu, além da variável $Y$ em cada um dos anos anteriores ao início da política em SP e no PR, a seguinte lista selecionada com seis possíveis preditores dos indicadores de resultado: nível médio de escolaridade (em anos de estudo), proporção de empregados com até 24 anos de idade, proporção de empregados na indústria, proporção de empregados homens, proporção de empregados que declaram ter cor branca, renda domiciliar per capita na UF.

Mais especificamente, foi utilizado o valor médio por unidade (UF ou grupo ocupacional, conforme o caso) dessas seis covariadas no período desde 2002 até o ano anterior à introdução da lei dos pisos salariais em SP (2006) e no PR (2005). Entretanto, em todos os exercícios, a rotina de minimização do EQM predito obteve as melhores aproximações entre unidades tratadas e seus respectivos grupos sintéticos atribuindo peso próximo a zero para todos os seis preditores; e distribuindo praticamente todo o peso entre os resultados anuais pré-tratamento da variável de resultado $Y$.

A título de exemplo, as tabelas A.3 e A.4 do Apêndice A mostram, respectivamente, a matriz $V$ e a matriz $W$ que levam ao resultado do exercício reportado na subseção 5.1. ${ }^{26}$ A tabela A.3 do Apêndice A exibe também os valores pré-tratamento da variável porcentagem abaixo do piso $(Y)$ e das médias das seis covariadas (matriz $Z$ ) observados na unidade tratada e em seu sintético construído. Nesse exemplo, como as covariadas recebem pequeno peso na minimização do EQM, é possível construir um sintético que não se parece com a unidade tratada em termos de alguns dos preditores. Quanto à proporção de pessoas brancas, em particular, a diferença é bem grande. Por sua vez, a unidade tratada e seu sintético se aproximam muito bem em termos da variável $Y$ em todos os anos do período pré-tratamento. Vale observar que os pesos finais das UFs que compõem o grupo de controle sintético são internos ao método, ou seja, eles não necessariamente levam em consideração dimensões como a proximidade espacial entre elas. Por exemplo, como mostra a tabela A.4 no Apêndice A, o Amazonas recebe um peso considerável na construção do grupo de controle do Paraná para o indicador da proporção que recebe abaixo do piso.

\subsection{Inferência}

A fim de fazer inferência sobre as estimativas obtidas dos efeitos de interesse, foi adotado também o método proposto em Abadie et al. (2010). Esse método

${ }^{26}$ As matrizes $V$ e $W$ dos demais exercícios realizados podem ser requisitadas aos autores. 
é inspirado no teste de permutação, que é comumente empregado na área de estatística e vem sendo cada vez mais aplicado em econometria. ${ }^{27}$ A ideia é comparar o efeito estimado para a unidade efetivamente tratada com estimativas do efeito em estudo, supondo-se que as unidades doadoras tivessem sido tratadas. Sob a hipótese de que a intervenção não afetou outras unidades além da unidade efetivamente tratada, a comparação das estimativas obtidas permite avaliar a distância entre a estimativa do efeito para a unidade tratada e as estimativas calculadas para as demais unidades. Quanto mais distante estiver a estimativa para o grupo tratado relativamente às demais estimativas, mais forte é a evidência de que o efeito do tratamento não ocorreu por acaso. Uma das vantagens desse método é que ele não demanda um número elevado de unidades pertencentes ao conjunto de unidades doadoras.

A operacionalização desse método de inferência foi realizada estimandose o modelo da subseção 4.1 separadamente para cada UF pertencente ao conjunto de unidades doadoras de SP ou PR. Especificamente, estimou-se para cada uma das 23 UFs desse conjunto a diferença entre os valores da variável de resultado para a UF e seu grupo sintético falseado. Durante o período pósintervenção, essa diferença de valores pode ser denominada efeito placebo. Procedeu-se de forma semelhante para as 58 unidades doadoras do grupo 1 de SP e para as 68 unidades doadoras do grupo 5 do PR.

\section{Resultados}

Conforme explicado na introdução, foram selecionados quatro indicadores para mapear em que medida os pisos salariais estaduais afetam o desempenho do mercado de trabalho: proporção de empregados com remuneração inferior ao valor do piso; taxa de emprego; grau de informalidade; e hiato salarial entre empregados com carteira e sem carteira. As subseções 5.1 e 5.2 analisam os resultados relativos aos dois primeiros e a 5.3 analisa os dois últimos.

\subsection{Proporção de empregados com remuneração inferior ao piso}

Os resultados foram obtidos mediante o emprego do método discutido na seção 4 em diversas agregações alternativas dos dados, tanto para PR como para SP. Para cada UF, os resultados serão reportados na forma gráfica tanto para o agregado das ocupações com piso legislado como para cada um de três grupos ocupacionais com diferentes valores de piso.

A primeira Figura será discutida em mais detalhes para que o leitor se acostume com a forma de apresentação das informações adotada até o fim do texto. A Figura 2 reporta quatro linhas referentes ao agregado das ocupações com piso no PR. As duas linhas intermediárias são de fundamental importância para a compreensão do método. A linha cinza contínua mostra a evolução de fato da porcentagem de empregados com remuneração abaixo do respectivo piso no PR entre 2002 e 2009 . A linha preta tracejada mostra a evolução deste mesmo indicador observada no grupo sintético que procura replicar a evolução no PR de fato durante o período anterior à criação do piso.

\footnotetext{
${ }^{27} \mathrm{O}$ teste de permutação é tipicamente realizado com base na construção da distribuição de uma estatística de teste (uma estatística $z$ ). Essa distribuição é obtida a partir da permutação aleatória das unidades da amostra entre os grupos de tratamento e de controle. Ver Angrist \& Krueger (1999) para uma discussão sobre o uso desse tipo de teste na área de economia aplicada.
} 
A linha do PR de fato (cinza contínua) mostra um claro declínio da parcela de trabalhadores com remuneração abaixo do piso entre 2005 (46,3\%) e 2007 $(37,2 \%)$, quando a política cobre todas as ocupações analisadas. Logo, uma simples comparação da evolução temporal desse indicador poderia levar à suposição de que a política tivesse feito diminuir em 9 pontos percentuais (p.p.) a proporção de trabalhadores com remuneração inferior ao piso. No entanto, a distribuição de rendimentos do PR pode ter sido afetada por outros motivos, alguns dos quais inclusive podem ter contribuído para diminuir a parcela de trabalhadores com renda menor que o piso. A evolução do grupo sintético tenta mostrar qual seria essa evolução quando afetada pelos demais fatores e sem a influência do piso. Segundo o método empregado, uma considerável parcela da queda desse indicador, quase 6 p.p., ocorreria mesmo sem a introdução do piso no PR. A estimativa do impacto do piso deve desconsiderar, portanto, essa parcela da queda que não pode ser atribuída ao piso.

A estimativa do efeito do piso consiste na diferença entre o PR e seu sintético, representada pela linha preta contínua, com valores orientados pelo eixo vertical da direita. Essa estimativa aponta que a introdução do piso induziu a uma queda de 2,7 p.p. na parcela de trabalhadores com remuneração inferior ao piso em 2006 e de 3,4 p.p. em 2007. Vale notar que o ajuste da evolução do grupo sintético à observada no PR no período pré-tratamento é quase perfeito. Isso dá suporte à interpretação de que as quedas de 2006 e 2007 se devem efetivamente à introdução do piso.

A linha cinza tracejada mostra a evolução em SC, inserida nesse gráfico para contrastar o método empregado com o diferenças em diferenças. Nas aplicações desse método para estimativas de efeito de pisos salariais estaduais, é praxe o uso de algum estado vizinho que não teve alteração no valor do piso como grupo de controle, com sua evolução no papel desempenhado aqui pelo grupo sintético. Em qualquer um dos casos, o grupo de controle deveria ser capaz de replicar a evolução do grupo de tratamento, mesmo que em patamar distinto, antes da criação do piso. A Figura 2 mostra que a coincidência ocorre quando se usa o grupo sintético como controle. A evolução reportada para esse grupo, como já mencionado, replica quase exatamente a evolução observada para o PR. Tanto nesse grupo de controle como no PR de fato, a porcentagem de trabalhadores recebendo uma quantia inferior ao piso fica estável entre 2002 e 2003, cai cerca de 3 p.p. de 2003 a 2004 e mais 1,5 p.p. entre 2004 e 2005. Por sua vez, a evolução observada em SC difere bastante desse padrão. Nesse estado, a porcentagem de trabalhadores com remuneração abaixo do piso paranaense sobe 2,5 p.p. entre 2002 e 2003 para em seguida cair 5,7 p.p. em 2004 e 3,4 p.p. em 2005.

Em comum com a Figura 2, os próximos gráficos trarão somente a linha preta contínua referente ao efeito do piso salarial, acompanhada de outras linhas que fazem parte do procedimento de inferência comentado na subseção 4.3. A Figura 3 dá sequência à análise da porcentagem de trabalhadores com remuneração abaixo do piso no PR e é a primeira de uma série com esse formato. As linhas finas e claras são usadas para inferência e representam diferenças análogas entre a evolução de cada uma das unidades não tratadas e seu respectivo controle sintético. Se a linha grossa for uma das mais distantes do zero em qualquer uma das direções, para cima ou para baixo, então se pode inferir que o grupo tratado foi realmente afetado.

No PR, a qualidade do ajuste do contrafatual é muito boa. Isto pode ser comprovado pela comparação no período pré-intervenção entre a linha 


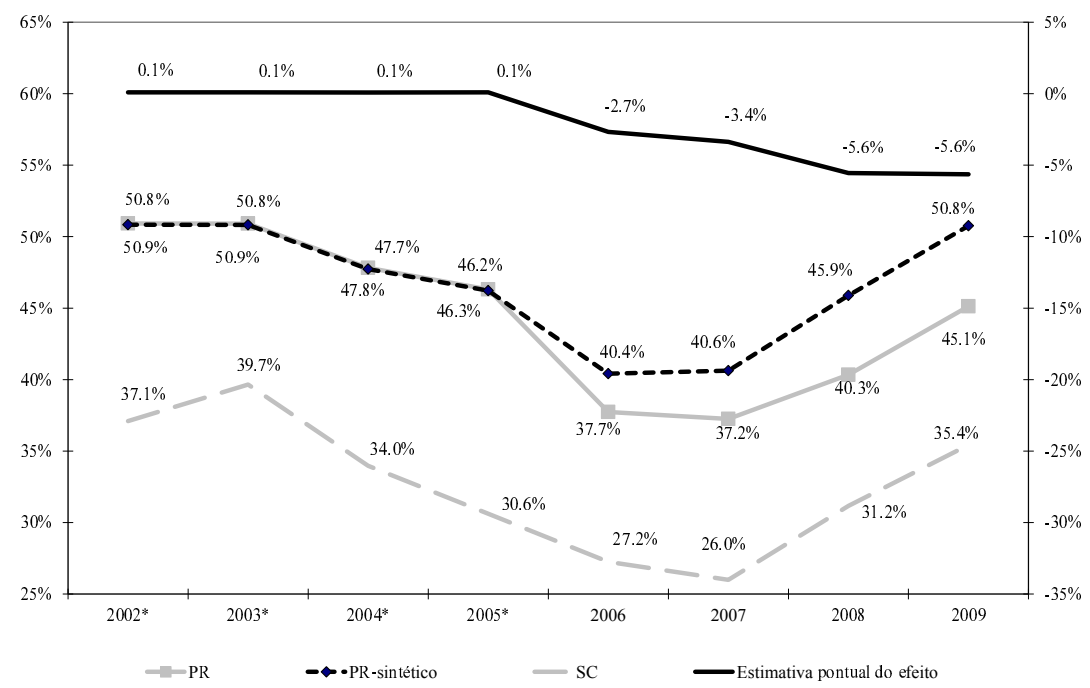

Fonte: PNAD/IBGE Elaboração dos autores.

* De 2002 a 2006, porcentagens com base no menor piso do PR em 2006, deflacionado pelo INPC até 2005.

Figura 2: Empregados com rendimento abaixo do piso e efeito da lei sobre esse indicador - Paraná*

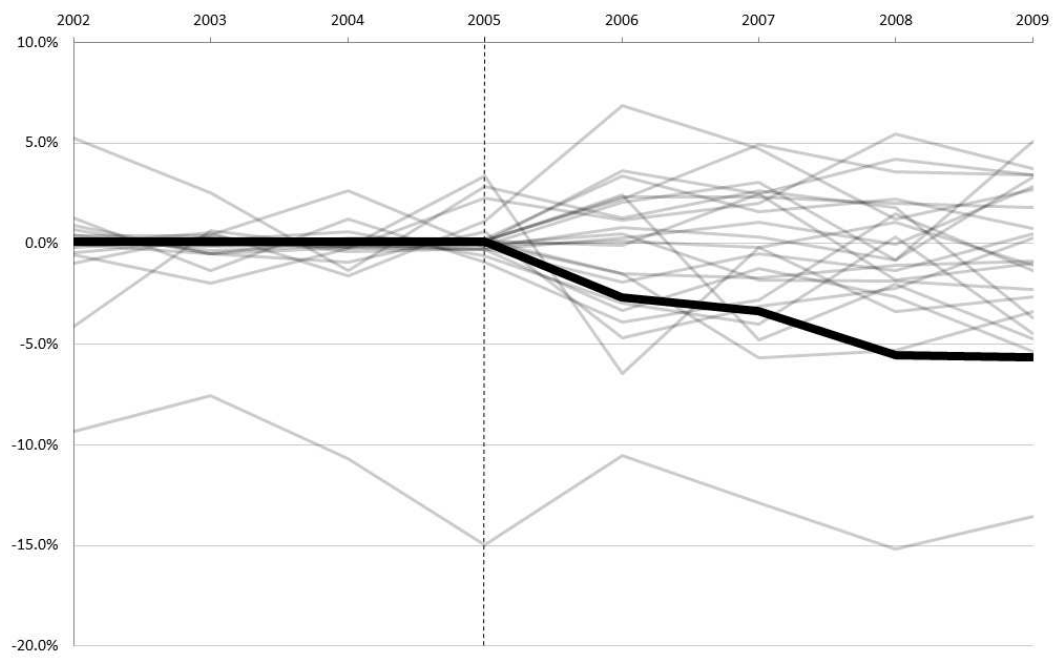

Fonte: PNAD/IBGE Elaboração dos autores.

Figura 3: Abaixo do piso: PR e demais UFs 
cheia e a que representa o zero, que aparecem sobrepostas. A trajetória póstratamento aponta a existência de algum efeito a partir de 2006, crescendo até se tornar significativo em 2008 e 2009 , quando a linha do PR passa a ser a mais negativa entre as UFs que se ajustaram bem aos seus respectivos sintéticos nos anos pré-tratamento. Na média de 2007 a 2009, período em que a legislação cobre todas as categorias estudadas, estima-se que 4,9\% dos empregados nas ocupações com piso no PR deixaram de ganhar menos que seus respectivos pisos devido à introdução da política. Isto equivale a 10,6\% dos empregados com ou sem carteira que supostamente ganhariam menos que o valor do piso se ele não existisse. Os resultados são similares - embora, curiosamente, um pouco menos significativos do ponto de vista estatístico - quando o exercício é reproduzido para uma amostra restrita somente aos empregados com carteira assinada.

A Figura 4 é feita de forma análoga para SP. Nessa UF o ajuste é bem precário, indicando que não foi possível agregar os trabalhadores das demais UFs sem pisos estaduais de forma a replicar a evolução em SP da proporção de empregados com remuneração abaixo do piso. A mesma conclusão vale para a amostra restrita aos empregados com carteira.

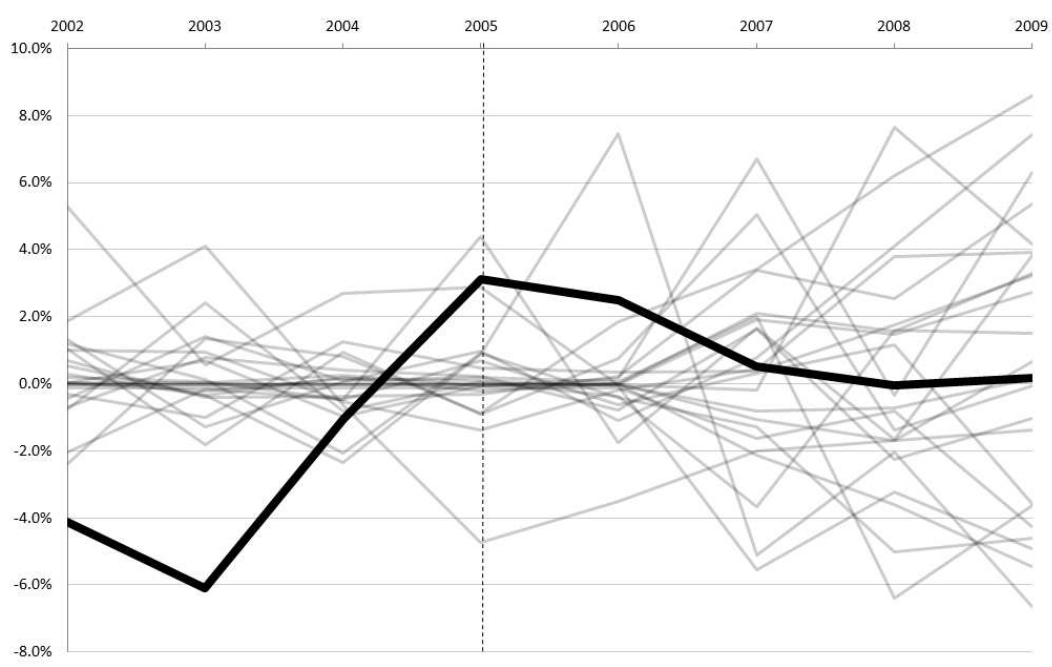

Fonte: PNAD/IBGE Elaboração dos autores.

Figura 4: Abaixo do piso: SP e demais UFs

O resultado - ou a falta dele - apontado para SP motiva a investigar cada um dos grupos ocupacionais de forma isolada. Mesmo no caso do PR, o aparente baixo efeito reportado pode ser fruto da agregação dos grupos ocupacionais.

Os próximos seis gráficos comprovam que há uma heterogeneidade do efeito entre os grupos e que ao menos um dos grupos ocupacionais de cada UF de fato teve a proporção de empregados com remuneração abaixo do piso afetada pelo piso. No caso do PR, as Figuras 5 a 7 mostram, em um extremo, o agregado de ocupações que corresponde ao GG 5 da CBO sendo claramente afetado. A Figura 5 indica que essa proporção caiu cerca de 8 p.p. dois anos após a introdução do piso. Vale lembrar que, em 2006, nem todas as ocupações do GG 5 da CBO estavam contempladas na legislação do piso paranaense, 
mas em 2007 todas passaram a ser contempladas. A estimativa é que, na média de 2007 a 2009, 5,4\% de todos os empregados do grupo 5 do PR tenham deixado de ganhar menos que seu piso por causa da legislação estadual. Essa porcentagem corresponde a $8,6 \%$ do contingente que supostamente receberia menos que o valor do piso caso a lei não existisse.

No outro extremo do caso paranaense, está o resultado para o grupo ocupacional 8 na Figura 7, no qual uma considerável parte das linhas cinzas abaixo da linha preta indica uma forte possibilidade de não haver efeitos significativos. A Figura 6 exibe resultados do grupo 6, para o qual, se há algum efeito, este parece ser marginal e restrito ao ano de 2006.

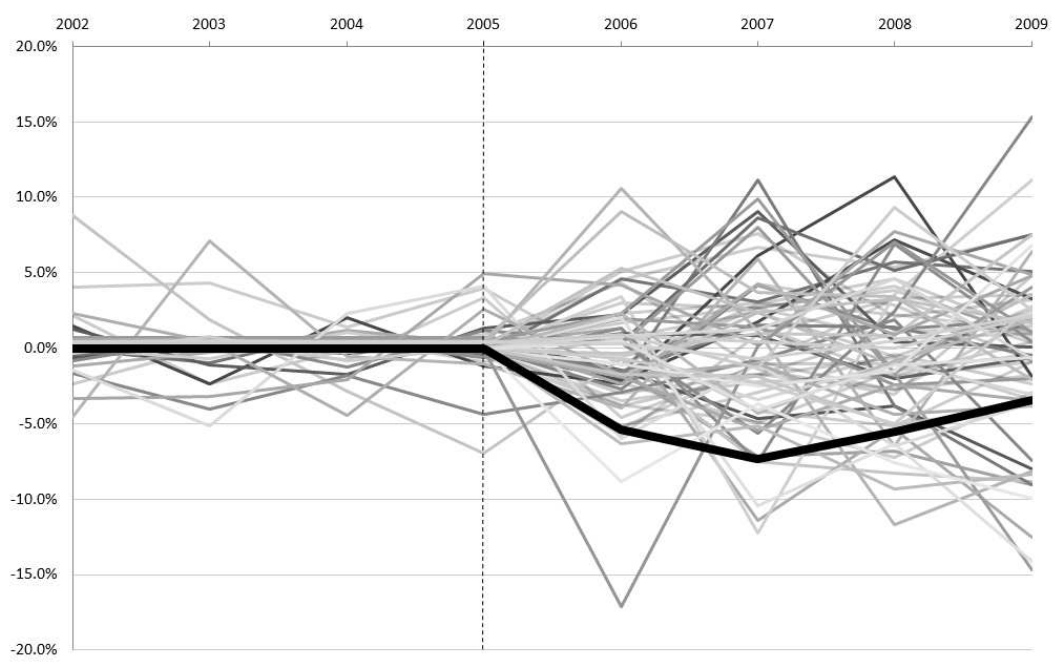

Fonte: PNAD/IBGE Elaboração dos autores.

Figura 5: Abaixo do piso: grupo 5 do PR e grupos das demais UFs

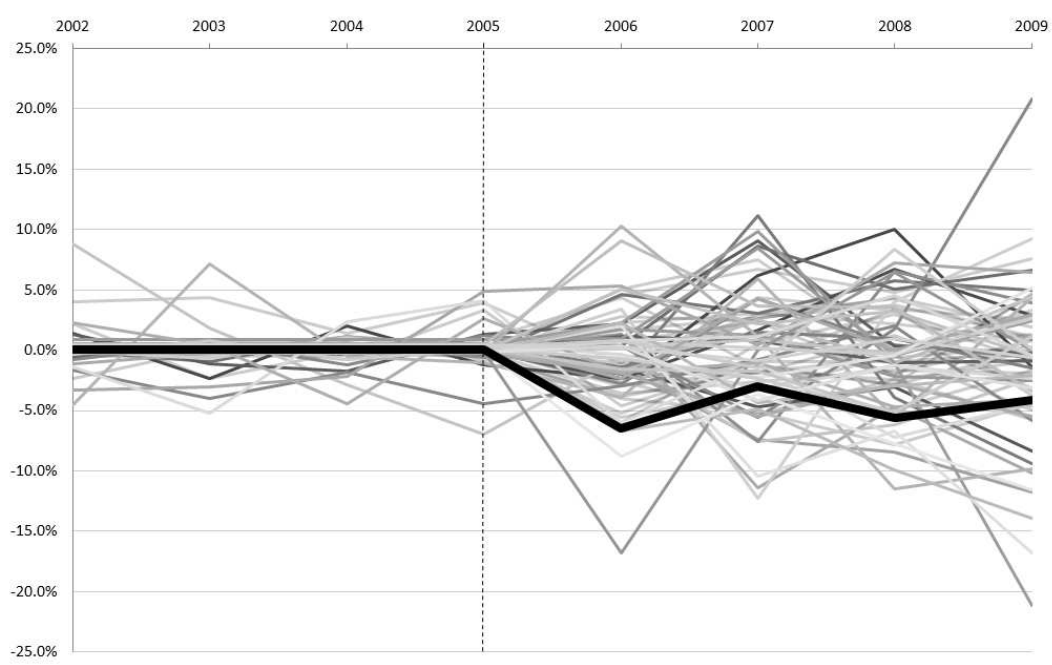

Fonte: PNAD/IBGE Elaboração dos autores.

Figura 6: Abaixo do piso: grupo 6 do PR e grupos das demais UFs 


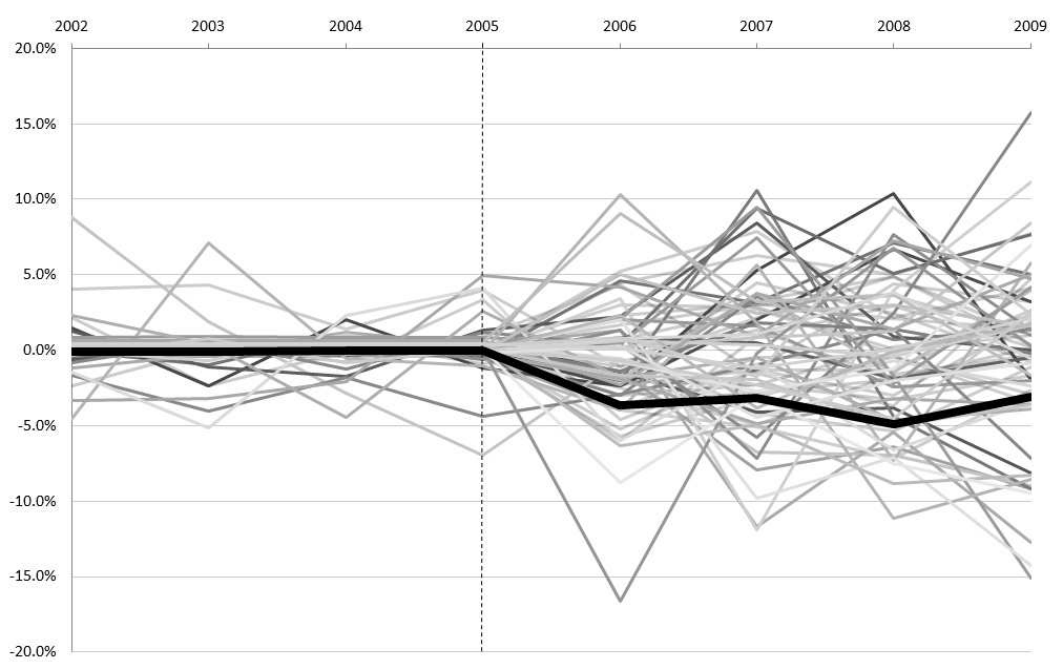

Fonte: PNAD/IBGE Elaboração dos autores.

Figura 7: Abaixo do piso: grupo 8 do PR e grupos das demais UFs

As Figuras 8 a 10 indicam que os grupos ocupacionais 2 e 3 têm efeitos não significativos, enquanto o grupo 1 apresenta um efeito significativo em 2007 e 2009, porém apenas marginalmente em 2008. A Figura 8 mostra que a proporção de trabalhadores do grupo 1 com remuneração abaixo do piso cai em relação à evolução do grupo de controle sintético. A diferença chega a 9,5 p.p. no primeiro ano de vigência do piso, 6,7 p.p. no segundo e 13,9 p.p. no terceiro. Estimou-se que, na média dos três anos analisados de vigência do piso, $10 \%$ dos empregados do grupo 1 de SP passaram a ganhar pelo menos tanto quanto seu piso devido à lei estadual. Em contraste ao caso de SP-agregado (Figura 4), o ajuste do grupo de controle sintético à evolução observada no grupo 1 antes do piso é muito bom.

Na Figura 9, o grupo 2 também apresenta um bom ajuste. Entretanto, esse grupo não parece ter sido afetado pelo piso. A Figura 10 mostra que o grupo 3 não teve ajuste suficiente para oferecer um resultado muito crível. Esse desajuste, no grupo mais bem remunerado de uma UF com salários relativamente altos, evidencia a dificuldade em se obterem grupos de controle adequados para grupos de tratamento muito próximos aos extremos, uma restrição válida também para outros métodos, embora nem sempre evidente em seus resultados.

Para confirmar se os efeitos reportados para a proporção de empregados com remuneração abaixo do piso, tanto no grupo 5 do PR como no grupo 1 de SP, são realmente provenientes da introdução dos respectivos pisos, foi conduzido um teste de falseamento. Nesse teste, simula-se que a política tenha sido introduzida um ano antes, ou seja, repetiram-se os respectivos exercícios de estimação e inferência como se o piso tivesse sido introduzido no PR em 2005 e em SP em 2006.

Se as Figuras apresentarem qualquer distanciamento nesses anos de tratamento placebo, é provável que o efeito capturado seja proveniente de outro fator, pois ainda não havia pisos legislados nesses anos. No caso do $\mathrm{PR}, \mathrm{o}$ método parece ser capaz de isolar o efeito do piso de outros efeitos. A Figura 11 mostra que as linhas para a evolução observada do grupo 5 e do seu 


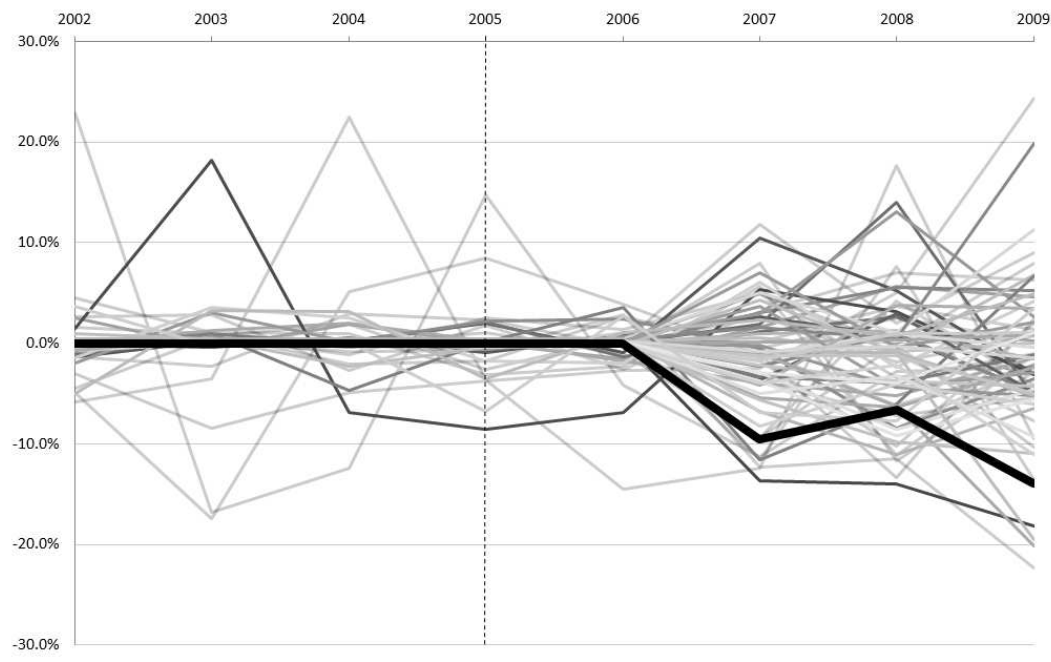

Fonte: PNAD/IBGE Elaboração dos autores.

Figura 8: Abaixo do piso: grupo 1 de SP e grupos das demais UFs

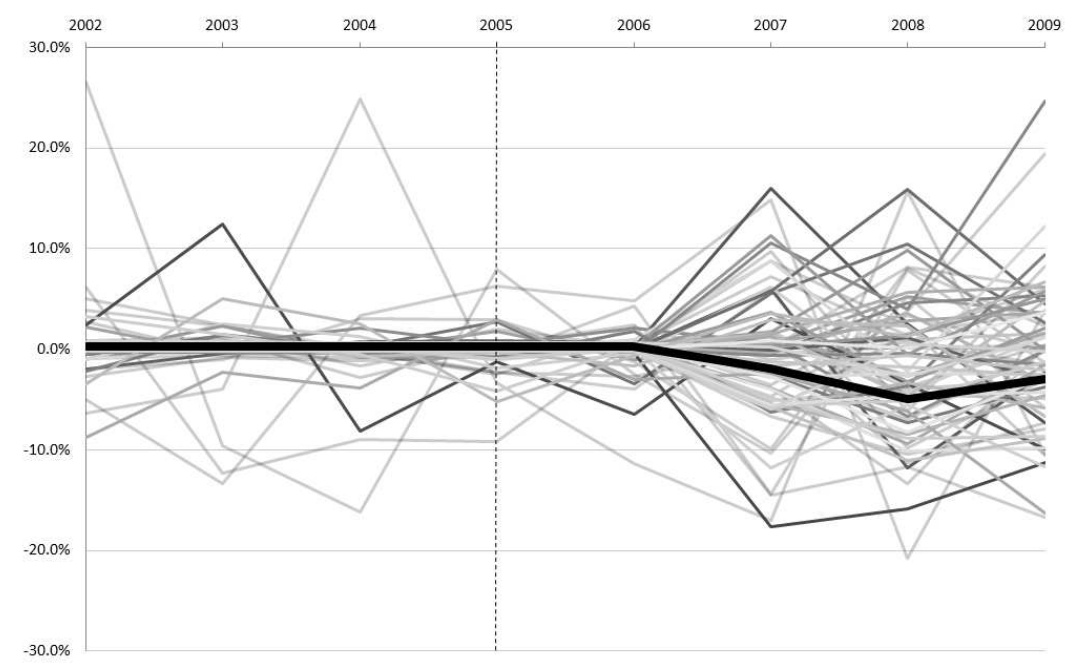

Fonte: PNAD/IBGE Elaboração dos autores.

Figura 9: Abaixo do piso: grupo 2 de SP e grupos das demais UFs 


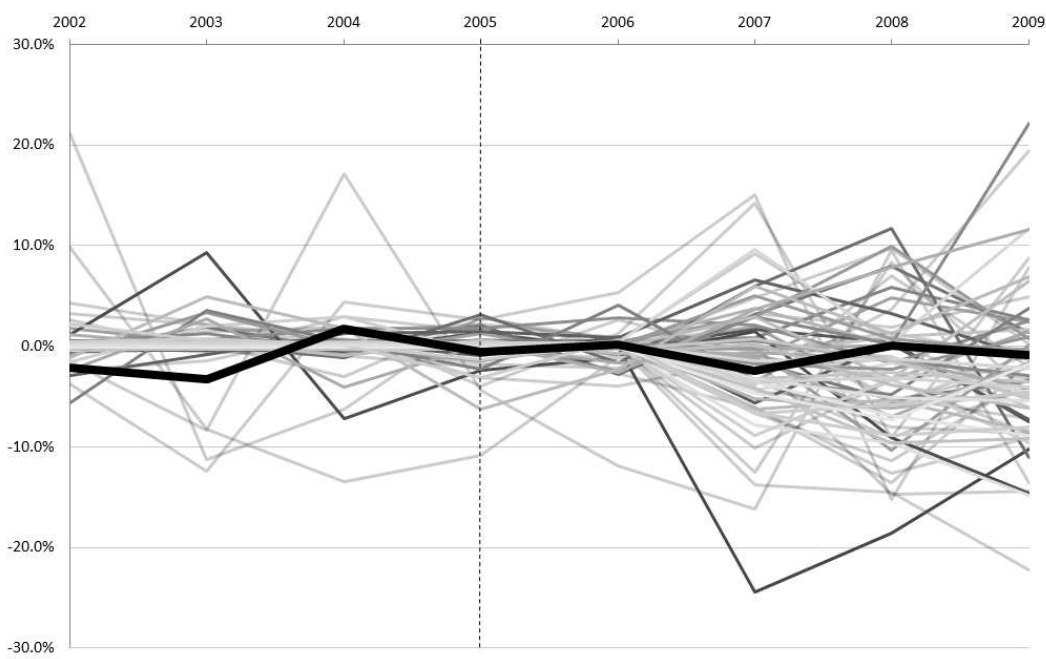

Fonte: PNAD/IBGE Elaboração dos autores.

Figura 10: Abaixo do piso: grupo 3 de SP e grupos das demais UFs

contrafatual continuam sobrepostas em 2005. Essa evidência reforça que o efeito reportado na Figura 5 pode ser atribuído aos respectivos pisos estaduais. No caso de SP, a Figura 12 aponta que o método talvez não consiga isolar de forma perfeita o efeito do piso, haja vista um distanciamento do zero já em 2006, antes da criação do piso. Isto significa que incluir ou não os dados de 2006 como critério de aproximação leva a grupos sintéticos com trajetórias diferentes. Esse fato suscita dúvidas sobre a capacidade de identificar um efeito realmente associado ao piso na Figura 8.

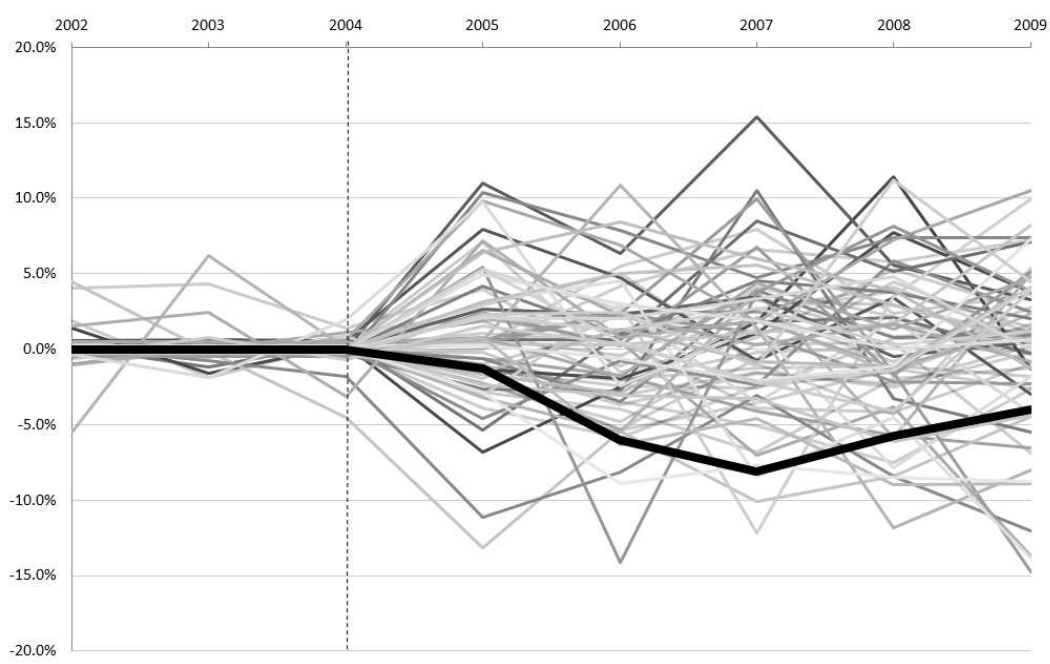

Fonte: PNAD/IBGE Elaboração dos autores.

Figura 11: Placebo em $t-1$ para abaixo do piso no grupo 5 do PR

Em suma, a análise do primeiro indicador apontou que apenas no grupo ocupacional 5 do PR e no grupo 1 de SP parece ter havido efeitos significativos dos respectivos pisos salariais sobre a proporção de trabalhadores com 


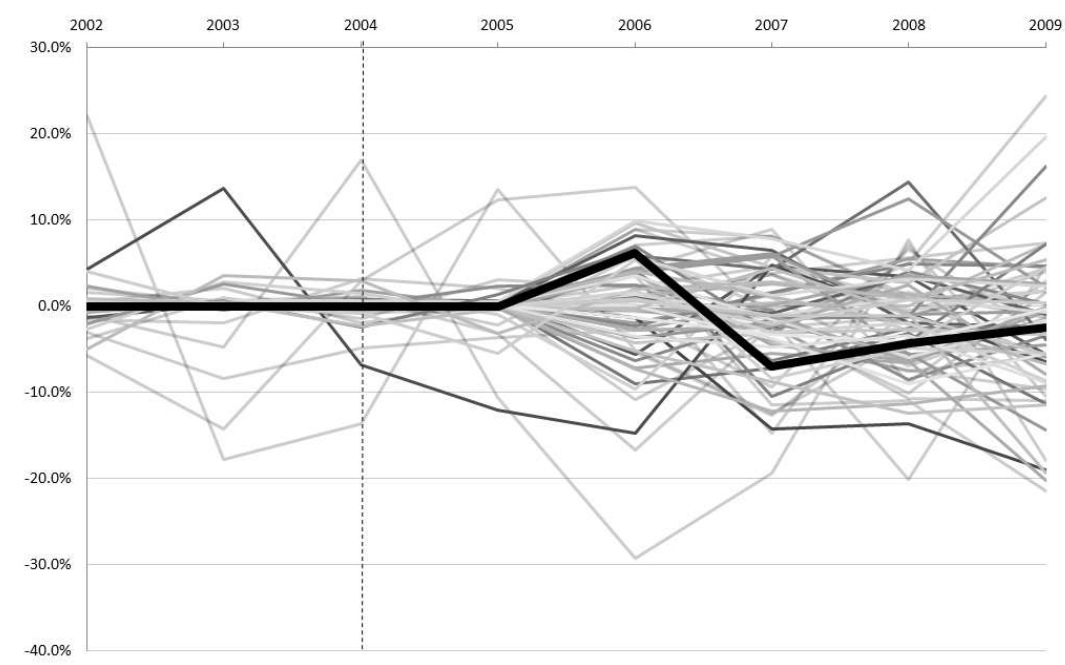

Fonte: PNAD/IBGE Elaboração dos autores.

Figura 12: Placebo em $t-1$ para abaixo do piso no grupo 1 de SP

remuneração abaixo desses valores. Para uma visão mais completa do ajuste do mercado de trabalho, passa-se à análise dos demais indicadores mencionados na introdução, quais sejam, a taxa de emprego, a taxa de informalidade e o hiato salarial entre empregados com e sem carteira assinada.

\subsection{Taxa de emprego}

As Figuras 13 e 14 mostram os resultados das estimativas de efeito dos pisos salariais do PR e de SP sobre a taxa de emprego, definida como a razão entre o total de empregados nos grupos com piso salarial e a PIA na respectiva UF. Em ambos os casos, não há evidência de efeito. A Figura 13 apresenta as estimativas para o PR, que tendem a ser próximas de zero, com o procedimento de inferência reforçando este fato em quase todos os anos. A Figura 14 traz os resultados para SP, em que o ajuste do grupo de controle sintético no período pré-tratamento deixa a desejar, o que não permite tirar nenhuma conclusão sobre o efeito a ser estimado.

Tal como foi visto na subseção anterior, é possível que a agregação dos grupos ocupacionais dilua eventuais efeitos presentes em ao menos um grupo isoladamente. Sendo assim, as Figuras 15 e 16 reportam os efeitos sobre a taxa de emprego nos grupos ocupacionais 5 do PR e 1 de SP. ${ }^{28}$ Em ambos os casos, há uma leve tendência de aumento desse indicador após a introdução dos pisos. As estimativas pontuais chegam a $0,7 \%$ da PIA do PR e a 0,5\% da PIA de SP na média de 2007 a 2009. Em ambos os casos, são aumentos estimados de 6,5\% no contingente empregado nessas ocupações em relação ao que se observaria na ausência dos pisos. Além de registrarem os maiores valores em cada um dos dois estados, os efeitos nesses grupos parecem ser os únicos com significância estatística.

\footnotetext{
${ }^{28}$ No caso das taxas de emprego calculadas para cada grupo ocupacional, vale notar que, enquanto o total de empregados é específico do grupo considerado, a PIA é agregada para a respectiva UF.
} 


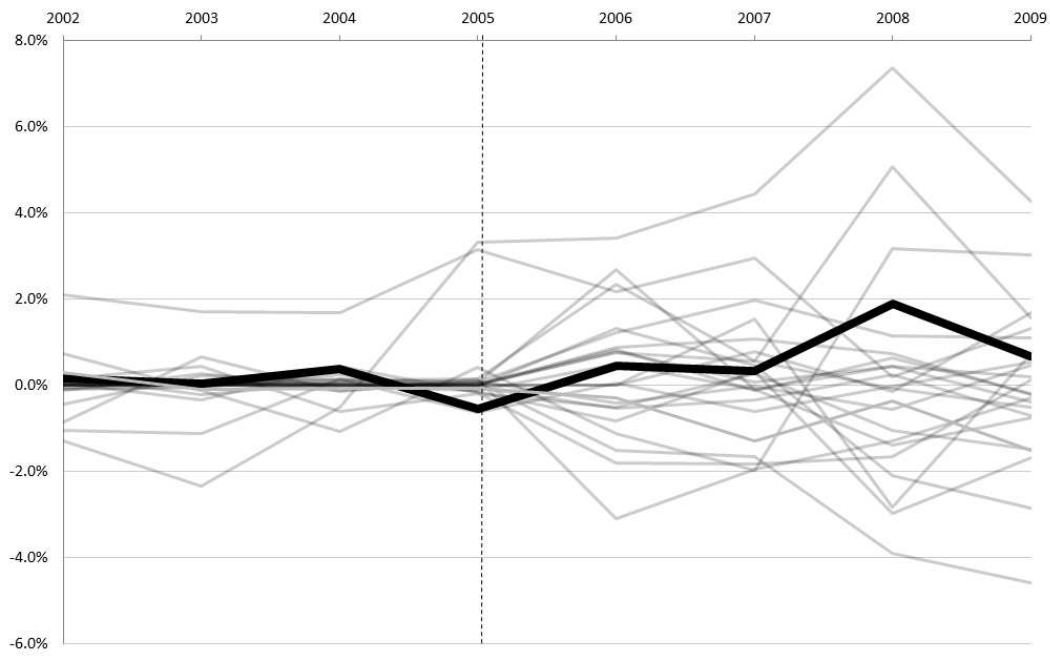

Fonte: PNAD/IBGE Elaboração dos autores.

Figura 13: Empregados com piso/PIA: PR e demais UFs

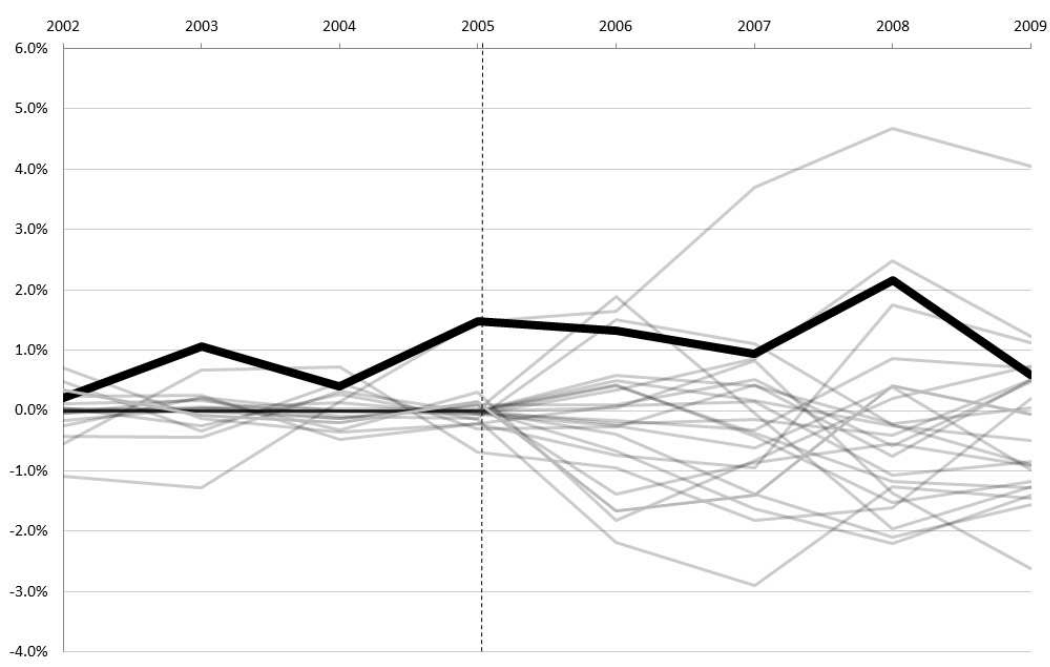

Fonte: PNAD/IBGE Elaboração dos autores.

Figura 14: Empregados com piso/PIA: SP e demais UFs 


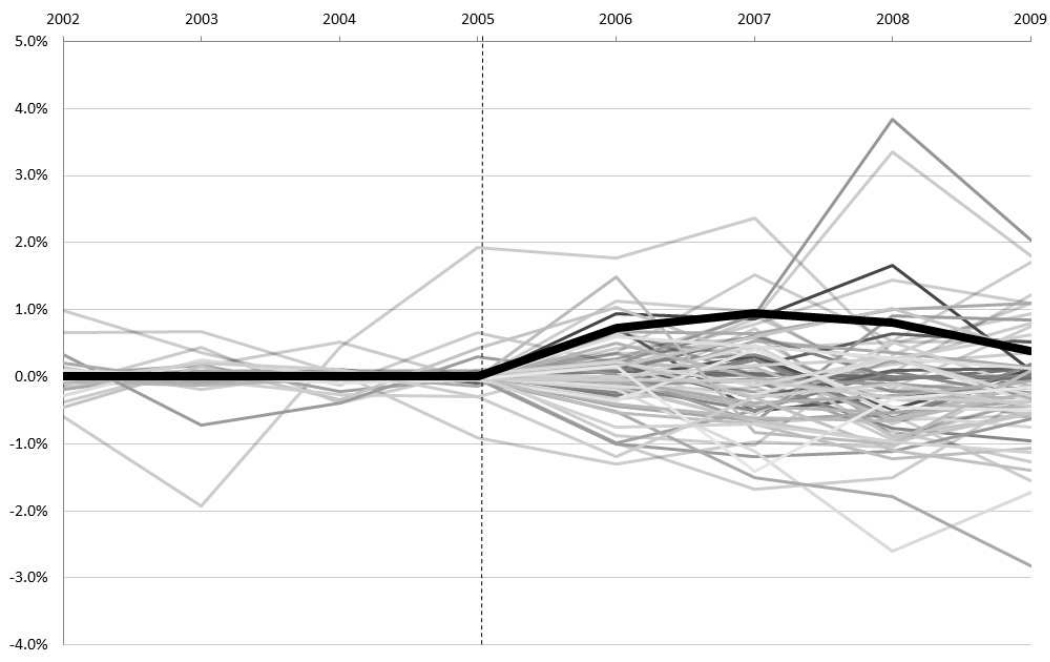

Fonte: PNAD/IBGE Elaboração dos autores.

Figura 15: Empregados/PIA: grupo 5 do PR e grupos das demais UFs

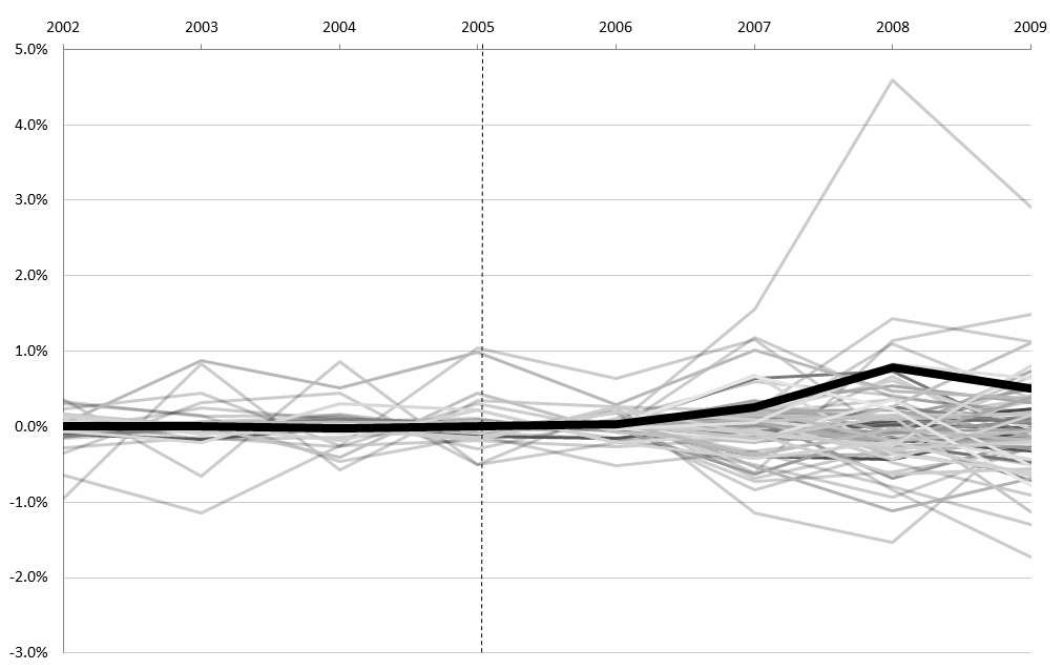

Fonte: PNAD/IBGE Elaboração dos autores.

Figura 16: Empregados/PIA: grupo 1 de SP e grupos das demais UFs 
Juntando-se as partes, as evidências são de que, ao menos em um grupo ocupacional de cada UF, a introdução do piso melhorou a distribuição de salários sem efeitos negativos sobre o emprego, que pode até ter reagido de forma positiva. Antes de avaliar a introdução dos pisos como benéfica para as ocupações em questão, resta saber se o aumento do emprego não foi fruto de um aumento no grau de informalidade.

\subsection{Taxa de informalidade e hiato salarial dos com e sem carteira assinada}

As Figuras 17 e 18 mostram os resultados para as taxas de informalidade entre empregados com e sem carteira de trabalho assinada no agregado das ocupações com piso no PR e em SP, respectivamente. No caso do PR, ilustrado na Figura 17, há uma clara indicação de que o piso salarial não teria afetado o grau de formalização dos empregados. A Figura 18 parece indicar uma tendência de declínio da informalidade para SP, ainda que não totalmente corroborada pelo método de inferência.

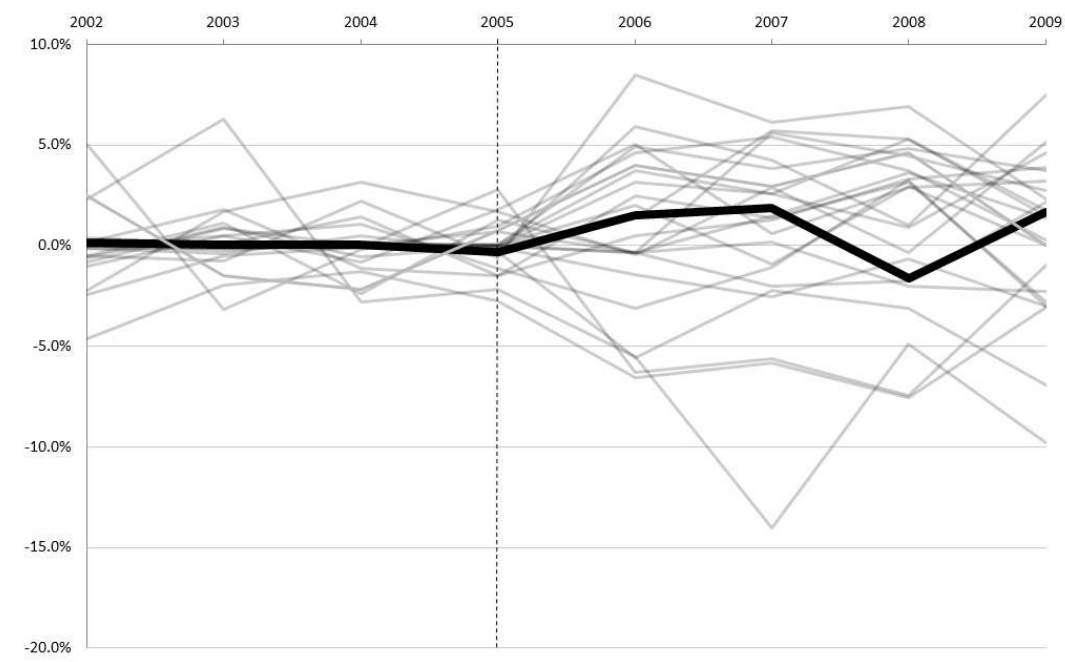

Fonte: PNAD/IBGE Elaboração dos autores.

Figura 17: Informalidade: PR e demais UFs

As Figuras 19 e 20 reportam o efeito dos pisos sobre o hiato salarial entre empregados com e sem carteira no agregado das ocupações com piso salarial tanto no PR como em SP. Nesse caso, os resultados apontam inequivocamente para um efeito nulo.

A análise dos efeitos dos pisos sobre o grau de informalidade e o hiato salarial foi repetida para os grupos ocupacionais 5 do PR e 1 de SP. Embora não apresentados, os resultados mostram que os pisos parecem não ter afetado nenhum dos dois indicadores dos grupos ocupacionais analisados. ${ }^{29}$

\footnotetext{
${ }^{29}$ Esses resultados podem ser requisitados aos autores.
} 


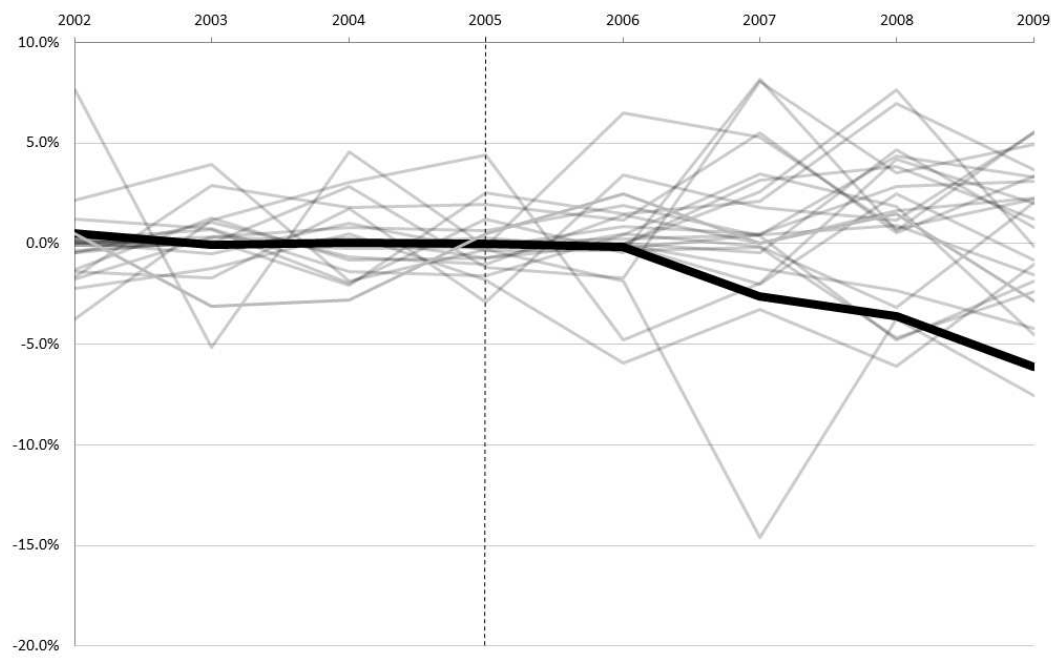

Fonte: PNAD/IBGE Elaboração dos autores.

Figura 18: Informalidade: SP e demais UFs

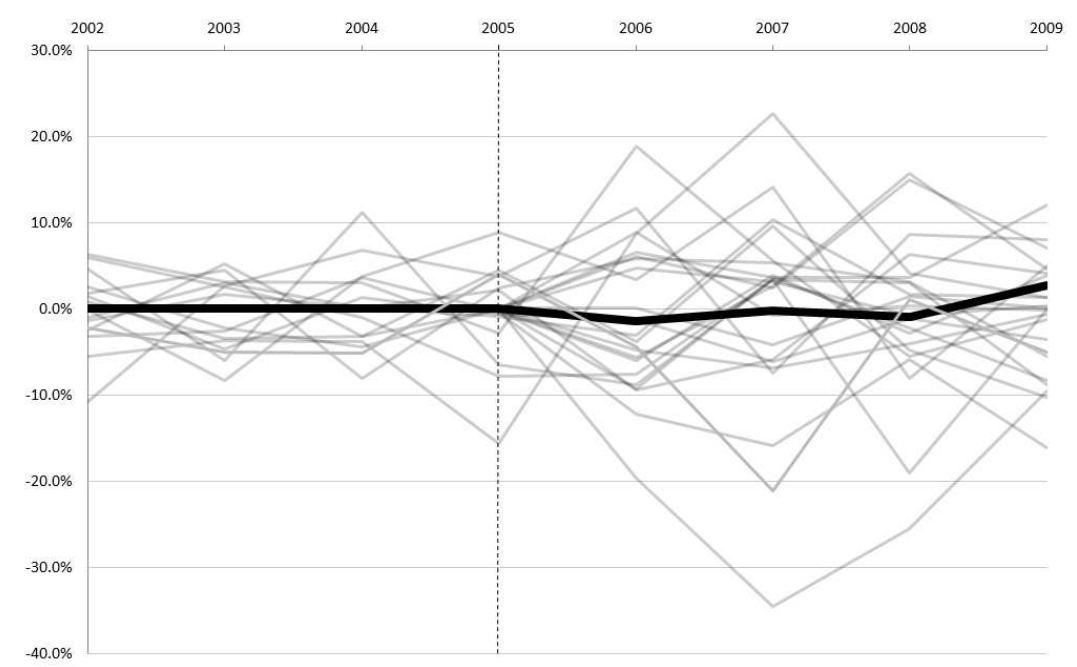

Fonte: PNAD/IBGE Elaboração dos autores.

Figura 19: Hiato salarial formal-informal: PR e demais UFs 


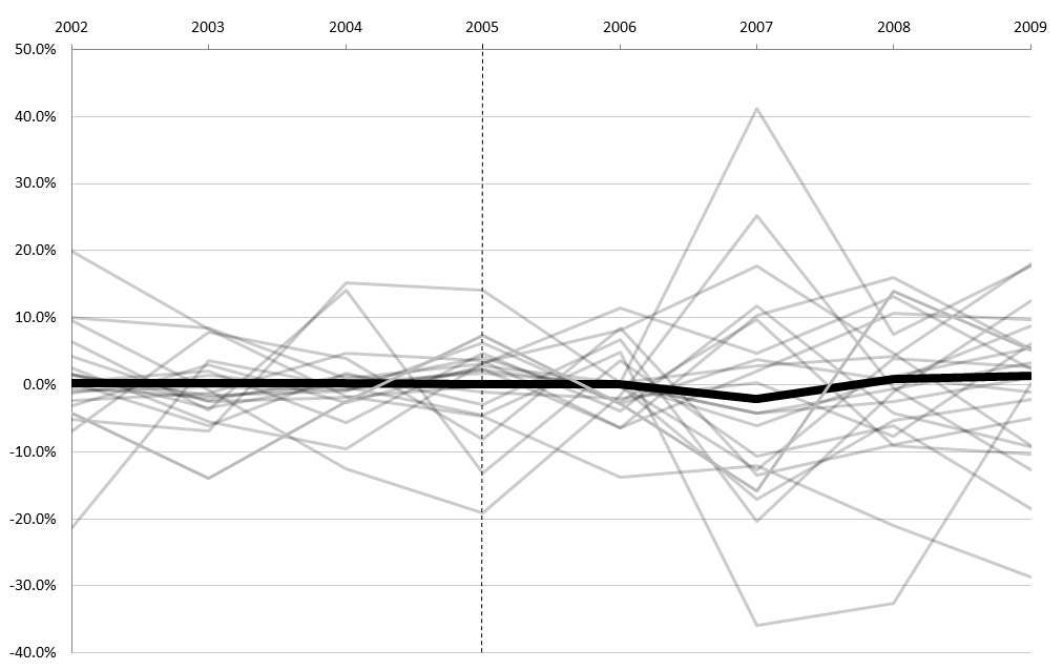

Fonte: PNAD/IBGE Elaboração dos autores.

Figura 20: Hiato salarial formal-informal: SP e demais UFs

\subsection{Discussão dos resultados}

Esta subseção discute, de forma especulativa, possíveis determinantes dos resultados descritos anteriormente. Estes resultados podem ser resumidos da seguinte forma. Tanto no PR como em SP, a introdução de pisos salariais teve efeitos heterogêneos entre os grupos ocupacionais analisados. ${ }^{30} \mathrm{Em}$ ambas as UFs, dois dos três grupos ocupacionais considerados não apresentaram efeitos significativos da introdução dos pisos sobre nenhum dos indicadores analisados. Esse fato seria condizente com uma baixa aderência dos contratos de trabalho aos valores legislados para esses grupos ocupacionais. Aparentemente, o trabalhador que seria remunerado em uma quantia inferior ao piso se ele não existisse permaneceu nesta situação na vigência do piso. $\mathrm{O}$ mesmo ocorreu com aquele que teria salário superior ao piso introduzido nessas respectivas ocupações. Não se descarta a hipótese de a lei ter sido ignorada para esses grupos ocupacionais. ${ }^{31}$

No entanto, os resultados do grupo ocupacional 5 do PR e do grupo ocupacional 1 de SP demonstram tanto algum grau de cumprimento da lei como um ajuste do mercado de trabalho dessas ocupações à introdução do piso. Os seguintes efeitos atribuídos à introdução do piso salarial foram documentados nestes grupos ocupacionais: i) diminuição da parcela de trabalhadores com remuneração abaixo do piso; $i$ ) aumento da taxa de emprego, ao menos no segundo ano após a introdução do piso; iii) taxas de informalidade inalteradas; e iv) diferenciais de salários entre empregados com e sem carteira assinada inalterados.

Dados os efeitos apontados nos dois primeiros itens, a aparente falta de efeito nos itens (iii) e (iv) sugere que os ganhos advindos da introdução do piso para empregos e salários não se restringiram ao setor formal. Não só o

\footnotetext{
${ }^{30}$ Cabe relembrar que os grupos ocupacionais utilizados neste artigo para SP e PR encontramse descritos no Apêndice $A$.

${ }^{31}$ Como mencionado na seção 2, Moura \& Neri (2008) para o RJ e RS e Chahad \& Pereda (2010) para SP também encontram baixa efetividade dos pisos salariais introduzidos nesses estados. $\mathrm{O}$ primeiro estudo também não encontra efeito do piso sobre o emprego.
} 
setor informal parece ter se beneficiado nessas dimensões, como parece tê-lo feito em proporções similares ao setor formal. Essas especulações estão em linha com a tese do efeito-farol já documentado em trabalhos anteriores sobre SM no Brasil (Foguel 1998, Neri et al. 2001).

Dessa forma, parece que a introdução dos pisos para os dois grupos ocupacionais foi absorvida pelos empregadores dessas ocupações sem que estes reduzissem o emprego ou passassem a informalizar seus contratos de trabalho. Ou seja, nessas ocupações os legisladores aparentemente conseguiram o resultado desejado em uma parte dos postos, sem os efeitos colaterais mais temidos. Assim mesmo, vale lembrar que a parcela dos postos com remuneração abaixo do piso ainda é bem significativa, conforme exposto nas tabelas 2 e 3 .

No que tange aos efeitos apontados sobre a melhora na distribuição de salários e o aumento na taxa de emprego, a literatura aponta três mecanismos alternativos compatíveis com tais resultados. O primeiro, mencionado na introdução, está relacionado aos modelos que atribuem algum poder de monopsônio às firmas no mercado de trabalho. Essa classe de modelos inclui desde aqueles tradicionais em que o poder de monopsônio é derivado de uma baixa densidade de firmas até os modelos de busca por emprego, em que o poder de monopsônio decorre da imperfeição na informação que flui para os trabalhadores sobre postos vagos. Nessa classe de modelos, as firmas podem não alterar seu nível de emprego frente a um aumento do piso salarial vigente ou mesmo aumentá-lo caso haja um aumento na oferta de trabalhadores dispostos a trabalhar pelo valor do piso.

O segundo mecanismo relaciona-se ao arcabouço de salário-eficiência, tal como sugerido por Rebitzer \& Taylor (1995). A principal característica deste arcabouço consiste em incorporar o nível de esforço que o trabalhador decide envidar na execução do seu ofício, em um ambiente em que a firma não consegue monitorá-lo de forma perfeita, mas o ameaça de demissão no caso de conseguir detectá-lo não se esforçando. ${ }^{32}$ Os autores demonstram que, para um valor de piso mais alto que aquele que induz o pleno esforço dos trabalhadores, porém não demasiadamente alto, tanto a introdução de um piso quanto o seu aumento tendem a aumentar o emprego. ${ }^{33}$

O terceiro mecanismo advém de modelos que levam em consideração o caráter parcial do cumprimento do piso. Em alguns desses modelos, há predições que apontam para o aumento do emprego sob certas condições relativas à capacidade do Estado em fazer a lei ser respeitada (Yaniv 2004).

Por fim, efeitos positivos de pisos salariais sobre o emprego são justificados na literatura também por argumentos centrados no estímulo à demanda por produtos advindos do aumento de rendimentos auferidos por empregados afetados pelo piso. ${ }^{34}$ Porém, no caso dos resultados aqui reportados, é preciso atentar que se observa um efeito positivo de emprego apenas para um grupo

\footnotetext{
${ }^{32}$ Por consequência, as firmas optam por pagar salários mais altos que aquele que equilibra o mercado de trabalho em pleno emprego. Dessa forma, os trabalhadores decidem sempre se esforçar.

${ }^{33}$ De forma intuitiva, o resultado se deve ao piso tornar desnecessário para a firma monitorar o esforço do trabalhador. Assim, os recursos empregados na atividade de monitoramento podem ser utilizados na ampliação da força de trabalho da firma.

${ }^{34}$ Um estudo interessante sobre impactos do SM que incorpora os efeitos de variação na renda dos trabalhadores é Fizbein (1992).
} 
ocupacional específico em cada estado. Logo, não é óbvio que o argumento via demanda por produtos justifique os resultados encontrados. ${ }^{35}$

\section{Conclusão}

Este trabalho apresentou uma avaliação dos efeitos dos pisos estaduais introduzidos no PR e em SP. Em ambas as UFs, foram analisados três grupos ocupacionais distintos com base nos dados da PNAD do IBGE para o período de 2002 a 2009. Chega-se à conclusão de que, em um dos grupos ocupacionais de cada UF, o piso parece ter aumentado a remuneração de trabalhadores que recebiam abaixo dos respectivos valores, sem que houvesse efeitos de contração da taxa de emprego ou aumento da informalidade. Em particular, o emprego parece ter até reagido de forma positiva nessas ocupações. Foram mencionadas algumas interpretações alternativas desse resultado com base na literatura internacional, que também já se deparou com efeitos sobre o emprego na mesma direção. Ainda para os mesmos grupos ocupacionais, foram encontradas evidências referentes à informalidade que corroboram a tese do efeito-farol.

Nos demais grupos ocupacionais, as evidências apontam que a lei foi ignorada pelas partes nas relações empregatícias, pois continuaram sendo pagos salários inferiores aos pisos em uma proporção tão alta quanto a verificada onde eles não existem.

Uma das principais contribuições deste trabalho foi a utilização de uma nova metodologia para identificar efeitos de tratamento em unidades agregadas. Trata-se do método de grupo de controle sintético apresentado por Abadie et al. (2010), mais flexível e baseado em um modelo mais geral que o de diferenças em diferenças, comumente empregado na literatura. Acredita-se que esse método possa ser útil em diversas outras aplicações em que tenha havido um experimento natural decorrente de uma mudança inesperada em alguma política local.

\section{Referências Bibliográficas}

Abadie, A., Diamond, A. \& Hainmueller, J. (2010), 'Synthetic control methods for comparative case studies: estimating the effect of california's tobacco control program', Journal of the American Statistical Association 105(490).

Abadie, A. \& Gardeazabal, J. (2003), 'The economic costs of conflict: a case study of the basque country', The American Economic Review 93(1).

Angrist, J. D. \& Krueger, A. B. (1999), Empirical strategies in labor economics, in O. Ashenfelter \& D. E. Card, eds, 'Handbook of Labor Economics', 1. ed. Elsevier. v. 3.

BLUNDELL, R. COSTA DIAS, M. (2009), 'Alternative approaches to evaluation in empirical microeconomics.', Journal of Human Resources 44(3).

\footnotetext{
${ }^{35}$ Seria necessária alguma hipótese adicional. Por exemplo, de que a demanda pelos bens e serviços intensivos na mão de obra cujos salários foram elevados pelos pisos fosse especialmente elástica à renda dos trabalhadores empregados em sua própria produção.
} 
Brasil (1988), 'Constituição da república federativa do brasil de 1988'.

Card, D. (1992), 'Do minimum wages reduce employment? a case study of california, 1987-1989', Industrial and Labor Relations Review 46, 38-54.

Card, D. \& Krueger, A. B. (1994), 'Minimum wages and employment: a case study of the fast-food industry in new jersey and pennsylvania', American Economic Review 84, 772-793.

Card, D. \& Krueger, A. B. (1995), Myth and measurement: the new economics of the minimum wage, Princeton: Princeton University Press.

Chahad, J. P. Z. \& Pereda, P. C. (2010), O comportamento e a avaliação da efetividade do piso salarial regional paulista, in 'ENCONTRO NACIONAL DE ECONOMIA, Bahia. Anais... Salvador: ANPEC'.

Corseuil, C. H. \& Servo, L. M. S. (2002), Salário mínimo e bem-estar social no brasil: uma resenha da literatura, Texto para Discussão 880, Ipea, Brasília.

Cunningham, W. (2007), Minimum wages and social policy: lessons from developing countries, Technical report, Washington: World Bank.

Danziger, L. (2009), 'Noncompliance and the effects of the minimum wage on hours and welfare in competitive labor markets', Labour Eonomics 16(6), 625630.

Danziger, L. (2010), 'Endogenous monopsony and the perverse effect of the minimum wage in small firms', Labour Economics 17, 224-229.

Dube, A., Lester, W. \& Reich, M. (2010), 'Minimum wage effects across state borders: estimates using contiguous counties', The Review of Economics and Statistics 92(4), 945-964.

Dube, A., Lester, W. \& Reich, M. (2011), Do frictions matter in the labor market? accessions, separations and minimum wage effects, Discussion Paper 5.811, IZA, Bonn.

Fajnzylber, P. (2001), Minimum wage effects throughout the wage distribution: evidence from brazil's formal and informal sectors, Texto para Discussão 151, Cedeplar, Belo Horizonte.

Fizbein, A. (1992), o workers in the informal sector benefit from cuts in minimum wage?, Working Paper 826, World Bank, Washington.

Foguel, M. (1998), Uma avaliação dos efeitos do salário mínimo sobre o mercado de trabalho no brasil, Texto para Discussão 564, Ipea. Rio de Janeiro.

Garloff, A. A. (2010), 'Minimum wages, wage dispersion and unemployment in search models: a review', Zeitschrift für Arbeitsmarkt Forschung 43, 145167.

Jatobá, J. \& Chahad, J. P. Z. (1997), 'O papel do salário mínimo no contexto da estabilidade econômica', Mercado de trabalho: conjuntura e análise (n. 3, Ipea, Rio de Janeiro).

Lemos, S. (2004), The effects of the minimum wage in the formal and informal sectors in brazil, Discussion Paper 1.089, IZA, Bonn. 
Masters, A. (1999), 'Wage posting in two-sided search and the minimum wage', International Economic Review 40(4).

Meyer, B. (1995), 'Natural and quasi-experiments in economics', Journal of Business and Economic Statistics 13, 151-161.

Mincer, J. (1976), 'Unemployment effects of minimum wages', Journal of Political Economy 84, 87-105.

Moura, R. L. \& Neri, M. C. (2008), 'Efetividade do "salário mínimo estadual": uma análise via regressões quantílicas para dados longitudinais', Economia Aplicada 12(2), 239-273.

Neri, M. (1999), Salário mínimo: o reajuste de 99, a desvinculação e a regionalização, Technical Report 45, Boletim Conjuntural. Rio de Janeiro.

Neri, M., Gonzaga, G. \& Camargo, J. M. (2001), 'Salário mínimo, “efeito farol” e pobreza', Revista de Economia Politica 21, 78-90.

Neumark, D. \& Wascher, W. (2000), 'Minimum wages and employment: a case study of the fast-food industry in new jersey and pennsylvania: comment', The American Economic Review 90, 1.362-1.396.

Rebitzer, J. \& Taylor, L. (1995), 'The consequences of minimum wage laws: some new theoretical ideas', Journal of Public Economics 56(2), 245-255.

Roppnen, O. (2011), 'Reconciling the evidence of card and krueger (1994) and neumark and wascher (2000)', Journal of Applied Econometrics 26, 1.0511.057 .

Saboia, J. (1984), Evolução histórica do salário mínimo no brasil: fixação, valor real e diferenciação regional, PNPE - Série Fac-Símile 15, Ipea. Rio de Janeiro.

Soares, F. V. (2004), Minimum wage and the informal sector in Brazil, Dissertation (philosophy doctor), University College London.

Swinnerton, K. (1996), 'Minimum wages in an equilibrium search model with diminishing returns to labor in production', Journal of Labor Economics 14(2), 340-355.

Ulyssea, G. \& Foguel, M. N. (2006), Efeitos do salário mínimo sobre o mercado de trabalho brasileiro, Texto para Discussão 1.168, Ipea. Rio de Janeiro.

Yaniv (2004), 'Minimum wage noncompliance and the sub-minimum wage rate', Economics Bulletin v. 10(n. 9), p. 1-7. 


\section{Apêndice A}

Tabela A.1: Composição dos grupos ocupacionais analisados no PR

\begin{tabular}{|c|c|c|}
\hline Grupo & Piso $^{(1)}$ & Grandes grupos da CBO 2002 citados na lei a partir de 2007 \\
\hline \multirow[t]{2}{*}{5} & II & $\begin{array}{l}\text { GG } 5 \text { - Trabalhadores dos serviços, vendedores do comércio em } \\
\text { lojas e mercados }\end{array}$ \\
\hline & I & GG 6 - Trabalhadores agropecuários, florestais, da caça e pesca \\
\hline \multirow{3}{*}{6} & III & GG 9 - Trabalhadores de manutenção e reparação \\
\hline & IV & GG 4 - Trabalhadores de serviços administrativos \\
\hline & VI & GG 3 - Técnicos de nível médio \\
\hline \multirow[t]{2}{*}{8} & V & $\begin{array}{l}\text { GG } 7 \text { - Trabalhadores da produção de bens e serviços industriais } \\
\text { (sistemas "discretos") }\end{array}$ \\
\hline & & $\begin{array}{l}\text { GG } 8 \text { - Trabalhadores da produção de bens e serviços industriais } \\
\text { (sistemas "contínuos") }\end{array}$ \\
\hline
\end{tabular}

Elaboração dos autores.

Nota: ${ }^{(1)}$ Seis faixas de pisos vigentes de 2007 a 2009. Em 2006, a lei definiu seis faixas de pisos para uma lista de ocupações específicas, mas, nas estatísticas deste estudo, foi atribuído o menor piso daquele ano aos grupos denominados 5, 6 e 8 indistintamente. Depois do período coberto na análise, as faixas II, III e IV foram fundidas em uma só. 
Tabela A.2: Composição dos grupos ocupacionais analisados em SP

\begin{tabular}{|c|c|c|}
\hline Grupo & Piso & Ocupações específicas conforme listadas na lei ${ }^{(1)}$ \\
\hline 1 & I & $\begin{array}{l}\text { Trabalhadores domésticos, serventes, trabalhadores agro- } \\
\text { pecuários e florestais, pescadores, contínuos, mensageiros } \\
\text { e trabalhadores de serviços de limpeza e conservação, tra- } \\
\text { balhadores de serviços de manutenção de áreas verdes e } \\
\text { de logradouros públicos, auxiliares de serviços gerais de } \\
\text { escritório, empregados não especializados do comércio, da } \\
\text { indústria e de serviços administrativos, cumins, barboys, } \\
\text { lavadeiros, ascensoristas, motoboys, trabalhadores de mo- } \\
\text { vimentação e manipulação de mercadorias e materiais e } \\
\text { trabalhadores não especializados de minas e pedreiras. }\end{array}$ \\
\hline 2 & II & $\begin{array}{l}\text { Operadores de máquinas e implementos agrícolas e flores- } \\
\text { tais, de máquinas da construção civil, de mineração e de } \\
\text { cortar e lavrar madeira, classificadores de correspondência } \\
\text { e carteiros, tintureiros, barbeiros, cabeleireiros, manicures } \\
\text { e pedicuros, dedetizadores, vendedores, trabalhadores de } \\
\text { costura e estofadores, pedreiros, trabalhadores de prepa- } \\
\text { ração de alimentos e bebidas, de fabricação e confecção de } \\
\text { papel e papelão, trabalhadores em serviços de proteção e } \\
\text { segurança pessoal e patrimonial, trabalhadores de serviços } \\
\text { de turismo e hospedagem, garçons, cobradores de trans- } \\
\text { portes coletivos, barmen, pintores, encanadores, soldado- } \\
\text { res, chapeadores, montadores de estruturas metálicas, vi- } \\
\text { dreiros e ceramistas, fiandeiros, tecelões, tingidores, tra- } \\
\text { balhadores de curtimento, joalheiros, ourives, operadores } \\
\text { de máquinas de escritório, datilógrafos, digitadores, telefo- } \\
\text { nistas, operadores de telefone e de telemarketing, atenden- } \\
\text { tes e comissários de serviços de transporte de passageiros, } \\
\text { trabalhadores de redes de energia e de telecomunicações, } \\
\text { mestres e contramestres, marceneiros, trabalhadores em } \\
\text { usinagem de metais, ajustadores mecânicos, montadores } \\
\text { de máquinas, operadores de instalações de processamento } \\
\text { químico e supervisores de produção e manutenção indus- } \\
\text { trial. }\end{array}$ \\
\hline 3 & III & $\begin{array}{l}\text { Administradores agropecuários e florestais, trabalhadores } \\
\text { de serviços de higiene e saúde, chefes de serviços de trans- } \\
\text { portes e de comunicações, supervisores de compras e de } \\
\text { vendas, agentes técnicos em vendas e representantes co- } \\
\text { merciais, operadores de estação de rádio e de estação de } \\
\text { televisão, de equipamentos de sonorização e de projeção } \\
\text { cinematográfica e técnicos em eletrônica. }\end{array}$ \\
\hline
\end{tabular}

Elaboração dos autores.

Nota: (1) Os secretários, excluídos da faixa de piso II a partir de 2009, foram desconsiderados nas análises deste estudo. Os técnicos em eletrônica, excluídos da faixa de piso III depois do período analisado, foram considerados. 
Tabela A.3: Valores e pesos de cada variável usada na minimização da diferença pré-tratamento para estimar o efeito sobre a porcentagem abaixo do piso no PR-agregado

\begin{tabular}{|c|c|c|c|}
\hline Variável & PR & PR-sintético & Peso na matriz $\mathrm{V}$ \\
\hline $\begin{array}{l}\text { Trabalhadores com remuneração abaixo do piso deflacio- } \\
\text { nado em } 2002(\%)\end{array}$ & 50,9 & 50,8 & 21,6 \\
\hline $\begin{array}{l}\text { Trabalhadores com remuneração abaixo do piso deflacio- } \\
\text { nado em } 2003(\%)\end{array}$ & 50,9 & 50,8 & 24,0 \\
\hline $\begin{array}{l}\text { Trabalhadores com remuneração abaixo do piso deflacio- } \\
\text { nado em } 2004(\%)\end{array}$ & 47,8 & 47,7 & 25,8 \\
\hline $\begin{array}{l}\text { Trabalhadores com remuneração abaixo do piso deflacio- } \\
\text { nado em } 2005(\%)\end{array}$ & 46,3 & 46,2 & 28,6 \\
\hline Subtotal 1: resultado pré-tratamento (\%) & & & 100,0 \\
\hline Renda domiciliar per capita (R\$) & 648,39 & 692,03 & $7,69 \mathrm{E}-27$ \\
\hline Escolaridade média (anos de estudo) & 7,67 & 7,84 & $3,23 \mathrm{E}-26$ \\
\hline Trabalhadores empregados na indústria (\%) & 24,5 & 20,0 & $7,22 \mathrm{E}-27$ \\
\hline Trabalhadores homens (\%) & 55,4 & 56,4 & $1,53 \mathrm{E}-26$ \\
\hline Trabalhadores de cor branca (\%) & 72,8 & 44,0 & $7,08 \mathrm{E}-26$ \\
\hline Trabalhadores com até 24 anos de idade (\%) & 30,8 & 30,9 & $1,45 \mathrm{E}-27$ \\
\hline Subtotal 2: covariadas & & & $1,35 \mathrm{E}-25$ \\
\hline Total $(\%)$ & & & 100,0 \\
\hline
\end{tabular}


Tabela A.4: Peso de cada UF na composição do PR-sintético para a porcentagem abaixo do piso

\begin{tabular}{lc}
\hline UF & Peso w $(\%)$ \\
\hline AM & 34,1 \\
DF & 33,4 \\
SC & 21,2 \\
AP & 2,9 \\
MT & 1,1 \\
RO & 0,9 \\
GO & 0,9 \\
MS & 0,8 \\
MG & 0,6 \\
ES & 0,6 \\
AC & 0,4 \\
PA & 0,4 \\
TO & 0,4 \\
RR & 0,3 \\
PE & 0,3 \\
BA & 0,3 \\
MA & 0,2 \\
CE & 0,2 \\
RN & 0,2 \\
PB & 0,2 \\
AL & 0,2 \\
SE & 0,2 \\
PI & 0,1 \\
\hline Total & 100,0 \\
\hline Fonte: PNAD/IBCE. Elaborac̃o dos autores.
\end{tabular}

Fonte: PNAD/IBGE. Elaboração dos autores. 
Tabela A.5: Frequência amostral por ano nas unidades tratadas e doadoras

\begin{tabular}{|c|c|c|c|c|c|c|c|c|c|}
\hline & Grupo & 2002 & 2003 & 2004 & 2005 & 2006 & 2007 & 2008 & 2009 \\
\hline \multirow{4}{*}{ Unidade tratada: PR } & 5 & 1795 & 1770 & 1862 & 1788 & 1949 & 1983 & 1964 & 2015 \\
\hline & 6 & 1113 & 1162 & 1271 & 1211 & 1223 & 1222 & 1361 & 1422 \\
\hline & 8 & 1373 & 1214 & 1491 & 1418 & 1461 & 1475 & 1561 & 1579 \\
\hline & Total & 4281 & 4146 & 4624 & 4417 & 4633 & 4680 & 4886 & 5016 \\
\hline \multirow{4}{*}{ Média das UFs doadoras } & 5 & 878 & 881 & 941 & 991 & 1022 & 1013 & 1007 & 1046 \\
\hline & 6 & 441 & 449 & 475 & 507 & 528 & 542 & 559 & 574 \\
\hline & 8 & 564 & 554 & 590 & 609 & 632 & 622 & 676 & 670 \\
\hline & Total & 1883 & 1884 & 2005 & 2107 & 2183 & 2177 & 2242 & 2289 \\
\hline \multirow{4}{*}{ Mediana das UFs doadoras } & 5 & 543 & 559 & 652 & 652 & 627 & 639 & 609 & 707 \\
\hline & 6 & 296 & 315 & 310 & 334 & 358 & 359 & 388 & 409 \\
\hline & 8 & 348 & 322 & 371 & 367 & 358 & 357 & 413 & 399 \\
\hline & Total & 1187 & 1196 & 1333 & 1353 & 1343 & 1355 & 1410 & 1515 \\
\hline \multirow{4}{*}{ Unidade tratada: SP } & 1 & 2960 & 3055 & 3049 & 3177 & 3331 & 3173 & 3194 & 3198 \\
\hline & 2 & 2755 & 2845 & 3017 & 3038 & 3174 & 3249 & 3301 & 2893 \\
\hline & 3 & 512 & 522 & 512 & 540 & 521 & 560 & 573 & 602 \\
\hline & Total & 6227 & 6422 & 6578 & 6755 & 7026 & 6982 & 7068 & 6693 \\
\hline \multirow{4}{*}{ Média das UFs doadoras } & 1 & 592 & 598 & 638 & 673 & 681 & 676 & 650 & 694 \\
\hline & 2 & 488 & 488 & 502 & 545 & 555 & 563 & 563 & 564 \\
\hline & 3 & 71 & 70 & 74 & 78 & 82 & 87 & 87 & 91 \\
\hline & Total & 1151 & 1156 & 1214 & 1296 & 1318 & 1326 & 1299 & 1349 \\
\hline \multirow{4}{*}{ Mediana das UFs doadoras } & 1 & 340 & 382 & 385 & 400 & 358 & 380 & 365 & 474 \\
\hline & 2 & 301 & 296 & 312 & 392 & 414 & 383 & 370 & 378 \\
\hline & 3 & 43 & 35 & 39 & 40 & 51 & 50 & 50 & 45 \\
\hline & Total & 684 & 713 & 736 & 832 & 823 & 813 & 785 & 897 \\
\hline
\end{tabular}

